Geopolítica(s) Revista de estudios sobre espacio y poder ISSN: 2172-3958

https://dx.doi.org/10.5209/geop.69203

\title{
Un nuevo sistema mundo desde el Sur Global: gran convergencia y desplazamiento geográfico acelerado
}

\author{
Víctor Ramiro Fernández ${ }^{1}$ y Luciano Moretti $^{2}$
}

Recibido: 4 de mayo de 2020 / Aceptado: 2 de octubre de 2020

Resumen. Desde inicios del nuevo siglo y bajo las transformaciones desplegadas en los últimos 50 años a partir de la crisis cíclica del capitalismo, tiene lugar un creciente desplazamiento espacial del proceso de acumulación hacia el Sur Global (SG). Tomando este último como unidad de análisis (y observando en su interior la interrelación de las macro regiones que lo componen), dicho desplazamiento es analizado a través de variables asociadas a su dinámica, dinamismo y creciente capacidad de control sobre las cadenas de producción global. Inserto todo ello en el marco de la explosión demográfica del SG, los resultados dan cuenta de una inédita alteración de la estructura jerárquica del capitalismo desde su nacimiento, al tiempo que abre un nuevo mapa para el examen de las jerarquías y su funcionamiento respecto del habitual esquema analítico (centro - semi-periferia - periferia) difundido por la teoría del sistema mundo. Una redefinición de la agenda analítica y estratégica se desprende de ello a nivel geopolítico y geoeconómico global.

Palabras clave: sistema mundo; Sur Global; capitalismo global; jerarquías; acumulación.

\section{[en] A New World System from the Global South: Great Convergence and Accelerated Geographic Displacement}

\begin{abstract}
Since the beginning of the new century and under the transformations unfolded in the last 50 years from the cyclical crisis of capitalism, takes place a growing spatial displacement of the accumulation process towards the Global South (GS). Taking the latter as the unit of analysis (and observing in its interior the interrelation of the macro regions that compose it), this displacement is analyzed through variables associated with its dynamics, dynamism and growing capacity to control the production global chains. Inserting all of this within the framework of the demographic explosion of the GS, the results show an unprecedented alteration of the hierarchical structure of capitalism since its birth, while opening a new map for the examination of hierarchies and their functioning with respect to of the usual analytical scheme (center - semi-periphery - periphery) diffused by the theory of the world system. A redefinition of the analytical and strategic agenda depends on it at the global geopolitical and geoeconomic level.
\end{abstract}

Keywords: world system; Global South; global capitalism; hierarchies; accumulation.

1 Instituto de Humanidades y Ciencias Sociales del Litoral (IHuCSO) -CONICET-, y Universidad Nacional del Litoral, Santa Fe (Argentina).

E-mail: rfernand@fcjs.unl.edu.ar

2 Universidad Nacional del Litoral, Santa Fe (Argentina).

E-mail: lmoretti@fcjs.unl.edu.ar 


\title{
[pt] Um novo sistema mundo do Sul Global: grande convergência e deslocamento geográfico acelerado
}

\begin{abstract}
Resumo. Desde o início do novo século e sob as transformações desdobradas nos últimos 50 anos a partir da crise cíclica do capitalismo, ocorre um crescente deslocamento espacial do processo de acumulação em direção ao Sul Global (SG). Tomando esta última como unidade de análise (e observando em seu interior a inter-relação das macrorregiões que a compõem), esse deslocamento é analisado por meio de variáveis associadas à sua dinâmica, dinamismo e capacidade crescente de controle das cadeias produtivas globais. Inserindo tudo isso no quadro da explosão demográfica da SG, os resultados mostram uma alteração sem precedentes da estrutura hierárquica do capitalismo desde o seu nascimento, ao mesmo tempo que abrem um novo mapa para o exame das hierarquias e seu funcionamento em relação às do esquema analítico usual (centro - semiperiferia - periferia) difundido pela teoria do sistema mundial. Uma redefinição da agenda analítica e estratégica depende disso no nível geopolítico e geoeconômico global.
\end{abstract}

Palavras-chave: sistema mundial; Sul Global; capitalismo global; hierarquias; acumulação.

Sumario. Introducción. 1. Debatiendo las jerarquías en el moderno sistema mundo y sus cambios: una perspectiva desde la Teoría del Sistema Mundo. 2. Precisiones metodológicas. 2.1. En relación al proceso de acumulación. 2.2. En relación al proceso de acumulación. 3. El surgimiento del Sur Global: ¿hacia una nueva gran divergencia? 4. De los flujos de producción a los flujos de intercambio: dinámica comparada del SG y su entrelazamiento interno. 5. El Sur Global manufacturero: de la desindustrialización a la re-industrialización. 6. Dinamización del proceso de acumulación bajo la lógica de funcionamiento en redes globales. 7. Control creciente a través de los actores trasnacionales. 8. Desafíos y posibilidades: resultados del boom demográfico del Sur Global. Mano de obra y demanda. Conclusiones. Referencias.

Cómo citar: Fernández, V. R., y Moretti, L. (2020). Un nuevo sistema mundo desde el Sur Global: gran convergencia y desplazamiento geográfico acelerado. Geopolítica(s). Revista de estudios sobre espacio y poder, 11(2), 313-344.

\section{Introducción}

Hacia el final del siglo XX, la crisis del capitalismo de los años 70s parecía para muchos superada, producto de una reconfiguración en las formas de acumulación y regulación que corrieron paralelas al derrumbe consecutivo de las experiencias del socialismo real. Algunos se animaban a presentar ese escenario como el triunfo definitivo del capitalismo representado en el "fin de la historia" (Fukuyama, 1988), antesala de un nuevo siglo signado por un "mundo plano" (Friedman, 2005) y el fin del Estado Nación (Ohmae, 1985). Hacia final del siglo, se consolida una "triada de poder" integrada por Estados Unidos, Alemania y Japón (Ohmae, 1985; UNCTAD, 1999), como espacio formador y configurador de la jerarquía de riqueza. Jerarquía que, a pesar de algunas fluctuaciones, al observarse en términos de ingresos per cápita, ha sufrido escasas alteraciones a lo largo del siglo XX (Arrighi y Drangel, 1986).

Sin embargo, a partir del nuevo siglo comienza una transformación de grandes dimensiones que desafía esa jerarquía. A la par de evidenciar las limitaciones crecientes de la hegemonía estadounidense, esa transformación representa una "contraofensiva" del Sur Global (SG), que lo coloca, bajo el liderazgo de Asia, como el principal protagonista del nuevo mapa geo-económico y geo-político global. 
Al observar al SG como unidad de análisis dentro de la unidad mayor del sistema mundo (SM), y al examinarlo a través de variables que dan cuenta de la dinámica, dinamismo y control del sistema de acumulación y de su densidad demográfica, observamos que aquella transformación desafía las estructuras consolidadas desde la emergencia del capitalismo europeo en el siglo XVI. Ello ha sido producto de la progresiva convergencia del SG con el Norte Global (NG) y del progresivo desplazamiento de éste último en el plano acumulativo. Esto, sobre la base del diferencial demográfico de ambos macro-espacios, representa una alteración en la jerarquía del SM, abriendo un nuevo escenario geopolítico y geoeconómico, con múltiples desafíos y posibilidades para el SG.

Esta afirmación, que es la hipótesis central de este trabajo, demanda aclarar dos aspectos de nuestro análisis. En primer término, no existe un cuestionamiento a la idea, predominante en el enfoque del análisis del sistema mundo, de que, miradas conjuntamente la riqueza y población, las diferencias históricas entre NG y SG se han mantenido, cuando no ampliado.

La propuesta sostenida aquí, sin embargo, pretende dislocar, a efectos analíticos, los aspectos cuantitativos y cualitativos del proceso de acumulación de aquellos asociados a la representación demográfica. En segundo lugar, el SG no puede ser analizado como una unidad homogénea, por lo que, junto al proceso de convergencia con - y desplazamiento de - el NG, el SG ha dado lugar a configuraciones macro regionales específicas en su interior, que en buena medida responden a la especificidad de sus trayectorias históricas. Estas últimas arrojan resultados marcadamente diferenciados entre las regiones que componen el SG, lo que deriva en vinculaciones políticas y económicas desde posicionamientos desiguales, que disparan interrogantes fundamentales en relación al escenario geoeconómico y geopolítico.

Para el desarrollo de la hipótesis, primero explicitamos la perspectiva teórica y metodológica desde la cual analizamos el reposicionamiento y convergencia del SG a nivel del proceso de acumulación junto a su predominio demográfico. Luego, analizamos el proceso empíricamente, a partir de la consideración sistemática de las dimensiones y variables presentadas, marcando junto a la convergencia del SG con el NG, diferentes trayectorias y configuraciones que tienen lugar en aquel gran conjunto regional.

\section{Debatiendo las jerarquías en el moderno sistema mundo y sus cambios: una perspectiva desde la Teoría del Sistema Mundo}

Nuestra hipótesis parte del análisis del SG en su totalidad, abriendo paso a una mayor profundización de la nueva jerarquía de relaciones que van emergiendo en su interior. No obstante partir de los aportes de la Teoría del Sistema Mundo (TSM), el enfoque asumido y los resultados que fundan dicha hipótesis contiene especificidades que abonan a formar un abordaje alternativo sobre la forma en que se estructura la dinámica global y el modo en que participa el SG en ella.

El foco analítico de la TSM parte del análisis del comportamiento del SM como unidad de análisis y entendido como un todo integrado. El desarrollo del sistema está auto-contenido; por lo tanto, los cambios suelen ser promovidos internamente (Wallerstein, 1976). La economía mundo capitalista que forma el moderno SM, 
contiene dos elementos centrales que viabilizan su comprensión. En primer lugar, se estructura sobre un sistema interestatal de múltiples jurisdicciones que compiten entre sí por territorio y recursos (Arrighi, 2007a). En segundo lugar, despliega cadenas de producción global mediante las cuales se configuran distintos espacios y lugares dando origen a una jerarquía de riqueza y poder, cualitativamente diferentes, dentro de una división internacional del trabajo (DIT) (Hopkins y Wallerstein, 1977; Hopkins y Wallerstein, 1986).

Esta economía mundo capitalista se ha desarrollado a lo largo de ciclos sistémicos de acumulación bajo el liderazgo de agencias estatales hegemónicas. Estos procesos cíclicos disparan crisis económicas y reconstituciones sistémicas donde predominan las soluciones de tipo espacial, a partir de nuevos ciclos, que recuperan nuevas bases de producción material, en nuevos territorios, con nuevos liderazgos dentro del sistema de competencia interestatal (Arrighi, 1994).

Durante el ciclo de hegemonía de los EE UU, esa configuración jerárquica cobró continuidad y una estabilidad escasamente alterada. Si bien durante el siglo XX se produjeron cambios a nivel de las actividades que se alojan en las cadenas y las actividades productivas que son relevantes para el posicionamiento en el centro o la periferia - tal como lo demostraron en su momento (Arrighi, 2003a; Arrighi y Drangel, 1986); y como también lo han señalado otros trabajos más recientes (Babones, 2005; Korzeniewicz y Moran, 1997; Pasciuti y Payne, 2017)-, no se generaron alteraciones significativas en la jerarquía de riquezas. Bajo esa estabilidad, el NG y la triada de poder formada por EE UU, Alemania y Japón (Ohmae, 1985), se consolidó como espacio de comando geoeconómico del SM, a pesar de la crisis sistémica iniciada a principio de los años 70 s y el progresivo debilitamiento hegemónico de EE UU. Mientras tanto, el superpoblado SG mantuvo su posición subalterna, realidad que se sostuvo hasta finales del siglo pasado.

Sin embargo, el nuevo siglo ha deparado un cambio de magnitud que redefine dicha jerarquía, marcando una serie de desafíos conceptuales para la interpretación de ese nuevo escenario. Algunos estudios sostienen que el ascenso del SG produce una convergencia con el NG tendiente a su igualación, como asumen viejos y nuevos idearios de la teoría de la modernización (Wolf, 2011; Sala-i-Martin, 2006). Sin embargo, más que una convergencia, el ascenso del SG representa una reconfiguración de la jerarquía, inscripta a su vez en una dinámica general de larga duración, donde imperan la estabilidad durante las etapas de hegemonía y las redefiniciones durante las crisis y períodos de caos sistémico (Karatasli, 2018).

Siendo ello significativo para interpretar el actual contexto de crisis y reconfiguración geo económica, es necesario dilucidar cuál es el alcance de ese nuevo escenario. En tal sentido, es preciso regresar a los aspectos cualitativos y estructurales que permiten comprender los cambios agregados $-\mathrm{y}$ de profundidad- asociados al reposicionamiento del SG.

Es importante observar que los trabajos que analizan las estabilidades y reconfiguraciones jerárquicas han sido planteados en términos de distribución de riqueza, analizando los productos per cápita. En estos análisis, el argumento ha estado asociado a la conformación de las relaciones de explotación y los procesos de exclusión de las cadenas de producción global, siendo esto el resultado de los posicionamientos desiguales y la inequidad de oportunidades de las diferentes naciones. $\mathrm{Su}$ posición relativa en la jerarquía de riqueza es correlacionada con desiguales oportunidades de esos espacios para obtener mejores ingresos y mantenerse en la 
delantera en la distribución y apropiación del excedente (Pasciuti y Payne, 2017); (Arrighi, 1990). Estos análisis han recibido no pocas y atendibles críticas como proxy para entender el posicionamiento sistémico de determinados espacios nacionales y/o regionales (Lourenço, 2005). Los resultados de esta distribución, y su interpretación sobre las movilidades o estabilidades sistémicas, no dan cuenta directamente de aquellos factores estructurales que operaron en los cambios en las jerarquías, y que hoy posibilitan una mejora en el posicionamiento en las cadenas globales por parte de los países del SG.

Nuestro argumento, en cambio, se sustenta en el análisis del desarrollo en el interior del SG de factores estructurales referentes a la estructura industrial y de conocimiento, que se encuentran en la base de las divergentes capacidades tecnológicas (Prebisch, 1986), y la apropiación de esas capacidades por parte de empresas líderes - de alcance trasnacional-, otorgando un control diferencial del proceso de acumulación de capital a ciertos espacios macro-regionales. En ello juega un papel central la acción estratégica de los Estados que, con distintas fortalezas, buscan enfrentarse a la fragmentación interna y la intromisión externa (Wallerstein, 2011).

Teniendo en cuenta esos aspectos estructurales, comprendemos lo que sucedió a partir de la crisis sistémica de los años 70s. Desde entonces, tuvo lugar un proceso de reestructuración y relocalización productiva que alteró la DIT, posibilitando la industrialización de la periferia (Frobel, Heinrichs y Kreye, 1980), no obstante que, por medio de este proceso, las regiones del SG no lograron, en general, avanzar en el control de esos factores estructurales. En consecuencia, buena parte del SG no logró reunir las capacidades para alterar la jerárquica, dado que, a pesar de la relocalización productiva por los capitales del centro, mucha de esa estructura industrial permaneció en el centro (Hudson, 2016; Dicken, 2011), al tiempo que ello no significaba la transferencia de los otros elementos señalados (control del conocimiento y de las empresas líderes). Ello generó que la industrialización del SG solo formase parte de una "ilusión del desarrollo" (Arrighi, 1990; Arrighi, Silver y Brewer, 2003), lo cual encontraba correlato en la escasa volatilidad zonal de los Estados en la distribución jerárquica de riqueza.

Sin embargo, la selección geopolítica por parte de los EE UU de determinados espacios durante la posguerra, particularmente en el Este asiático (Stubb, 1999; Glassman, 2018), permitió habilitar allí una industrialización que logró formar una plataforma productiva industrial de base local y regional, con inserción en las redes económicas globales. A partir de un direccionamiento estatal idiosincrático, permitió la emergencia, continuidad y profundización de los factores estructurales que posibilitaron un ascenso en la jerarquía de riqueza (Amsden, 2003; Wade, 1990; Evans, Rueschemeyer y Skocpol, 1985). El Este asiático hizo visible su dinamismo a lo largo de los años 80s (Arrighi, Satoshi y Irwan, 1993), aumentando su impulso con la disruptiva incorporación de China, a partir de las últimas décadas del siglo XX.

Desde el inicio del siglo XXI, el SG devino en el espacio dinamizador del proceso de acumulación y, bajo un visible liderazgo del dinamismo acumulativo en Asia (Arrighi, 2003b), se constituyó en la plataforma de una nueva fase productiva de expansión material que contrasta con la financialización del NG (Epstein, 2006). Bajo ese dinamismo, se constata la presencia de un enorme macro-espacio surcado por crecientes flujos de intercambio y cadenas globales forjadas en su interior. Esto 
da como resultado un dinamismo del proceso acumulativo que contrasta con el comportamiento del NG, que no obstante preservó su posición de supremacía en los factores estructurales hasta finales del siglo pasado. Este proceso representa, más que una ilusión de desarrollo, una creciente realidad que se expresa en el enorme desplazamiento geoeconómico global. Se trata de un cambio tectónico de placas que resalta la relevancia de comprender cómo opera la periferia sobre el centro (Hall, 1996), y de cómo ella y sus especificidades regionales pueden actuar sobre el conjunto del SM, a partir de sus transformaciones y sus heterogeneidades y relaciones internas.

Nuestra propuesta es observar en forma comparada el desarrollo del SG respecto al $\mathrm{NG}$, con foco en aquellos elementos estructurales vinculados al control y dinámica del proceso de acumulación, destacando paralelamente algunas de sus importantes heterogeneidades internas. Tomamos al SG como una unidad específica, y analizamos el tránsito desde su condición subalterna hacia su progresiva reversión a partir del nuevo siglo. Dentro de ello, procuramos destacar el papel de las regiones que forman parte de la lógica sistémica (Hamashita, 1994; Ikeda, 1996) e integran el SG. Hacemos ello mostrando aspectos diferenciadores que asumen las trayectorias de las macro regiones (particularmente de Asia respecto del "resto"), dentro de la configuración e interrelación creciente del $\mathrm{SG}$, en lo que respecta al control y dinámica del proceso acumulativo.

Bajo dicho análisis, la dimensión demográfica asume un rol diferenciado respecto de la perspectiva de SM. Si bien, come esta sostiene, se generan desigualdades de ingreso que se traducen en desigualdades espaciales, es necesario considerar, también, las desigualdades demográficas que se remontan a trayectorias históricas milenarias (Gunder Frank, 1998). Esto aplica particularmente para aquellas regiones geográficas que por sus condiciones medioambientales han generado una alta densidad poblacional basada en tasas sostenidas de natalidad (por ej. India o China).

En este sentido, los países que conforman el centro del SM han incluido, históricamente, tan solo al 15\% de la población mundial, mientras que el resto acumula el 85\% restante (Karatasli, 2016). Bajo el proceso de retorno económico de Asia, transitamos una inédita convergencia entre el espacio donde se radican los elementos estructurales que generan el dinamismo y control del proceso de acumulación y aquel donde reside la mayoría de la población mundial. Este hecho, de enorme magnitud, desafía la formación de nuevas lógicas de organización productiva y espacial, al tiempo que genera nuevos focos de tensión en la búsqueda de la supervivencia ambiental.

Es en el marco de esta estrategia que buscamos sopesar y dislocar la dimensión demográfica en una doble dirección que propone superar cierta linealidad devenida del análisis del PBI per cápita. Es decir, en la asociación del volumen de riqueza acumulado con el peso demográfico relativo de cada espacio nacional/regional. $\mathrm{Al}$ escindir dicha asociación, se hace factible considerar la relevancia nacional y macro-regional en la dinámica del proceso de acumulación en el conjunto, más allá de la dimensión demográfica. A su vez, nos permite considerar el peso que una masa poblacional tiene en las problemáticas de la organización social, económica y ecológica. 


\section{Precisiones metodológicas}

Para observar el movimiento ascendente del SG en el sistema mundo atendemos a la consideración de las siguientes tres dimensiones del proceso de acumulación: dinámica, dinamismo y control diferencial del proceso de acumulación.

\subsection{En relación al proceso de acumulación}

El análisis de la dinámica se realiza a través de aquellas variables que atienden al comportamiento de los flujos que forman la producción, la inversión y el intercambio, otorgando una atención particular al comportamiento industrial. La consideración del dinamismo se efectúa a través de aquellas variables que aseguran y potencian los procesos de valorización y la cualificación en el posicionamiento de las redes económicas globales, a través de la generación de conocimiento y su traducción en formas de innovación y aprendizaje mediante la inversión tecnológica. Finalmente, el control significa la observación de la generación de los actores económicos (de base trasnacional), capaces de controlar/incidir de manera dominante en las redes de producción global.

La dinámica de acumulación del proceso acumulativo se observa a partir de tres ejes. El primer eje analiza la representación a nivel espacial del proceso de acumulación desde una perspectiva histórica de larga duración. Tomando como punto de partida el origen de la divergencia entre $\mathrm{SG}$ y el NG, consideramos la desigual distribución y dinámica de los procesos de producción e intercambio expresados en la evolución del PBI (general y per cápita) y su distribución comparada entre el NG y el SG, y damos cuenta de como participan el SG y el NG en el total de la producción mundial.

El segundo eje examina los flujos de interrelación que tienen lugar entre el NG y el SG y al interior de esos espacios. Los observamos a través del comportamiento/participación de esas áreas del sistema mundo en el intercambio comercial y las inversiones externas, dando cuenta del dinamismo interno del gran área del Sur y de su movimiento ascendente como una gran placa tectónica al ser considerado "como un todo" (UNCTAD, 2015a; Bernhardt, 2016).

El tercer eje se asocia con las particularidades de la participación en el valor agregado manufacturero, observado en sus dimensiones tanto cuantitativas como cualitativas. El desarrollo de una base manufacturera habilita la maduración del proceso de acumulación y su sostenibilidad en el tiempo debido a los efectos asociados al crecimiento de la productividad y el estímulo de enlaces productivos y tecnológicos (Chang, 2002; Amsden, 2003).

El dinamismo se analiza a partir de la distribución de la inversión en $\mathrm{I}+\mathrm{D}$ y de la cantidad de patentamientos por espacio geográfico. La inversión en I+D se traduce en una mayor capacidad de los agentes capitalistas de controlar eslabones claves de las cadenas de valor global (Pietrobelli y Rabelloti, 2011), lo que posibilita retener el capital en sus territorios, marcando la diferencia entre centro y periferia.

Finalmente, el examen del control actoral se centra en las empresas trasnacionales que dominan las redes económicas globales que caracterizan el actual patrón reproductivo del sistema, y que se emplazan diferencialmente en el centro y periferia del sistema mundo. Esto lo realizamos a través de la evolución de la ubica- 
ción/pertenencia de las sedes de las principales Empresas Trasnacionales (ETS) globales (Gereffi, 2001; Fernández, 2017).

\subsection{En relación con la representación demográfica}

La población ha sido observada preferentemente para relativizar la presencia de espacios, particularmente periféricos, al ser cruzados con la configuración de la producción per cápita. Como indicamos en el apartado teórico, este método presupone que un mayor PBI per cápita viene de la mano de los componentes económicos estructurales, que explican las transformaciones en la jerarquía de riqueza. Este método también ha sido tendencialmente ligado para indicar el distanciamiento en el nivel de desarrollo con otras áreas del sistema mundo e incluso inducir la participación en las cadenas (Arrighi y Drangel, 1986). Desde esta perspectiva dominante se infiere que, a más población en el mismo PBI, menor desarrollo.

Sin embargo, asume relevancia para observar cuál es la población que los procesos de acumulación representaron, representan y representarán en el futuro. En un contexto de ralentización general del crecimiento poblacional y de aumento de las expectativas de vidas globales (United Nations, 2015), la dinámica y configuración etaria alcanzan formas de distribución marcadamente diferentes en el SM. Esto no resulta inocuo, dado que la presencia, dinámica y proyección demográfica se asocian a múltiples procesos ligados al campo medioambiental, migratorio, del empleo, el consumo, la producción, entre otros, que comprometen las sendas de desarrollo.

La consideración de las dimensiones acumulativa y demográfica, observadas conjuntamente, da cuenta de una realidad que no expresa un mero descentramiento productivo y de flujos controlados por el norte. Habilita, por el contrario, una renovada lectura vinculada a un momento inédito dentro del SM en el que, luego de que la gran divergencia generara que una parte minoritaria de la población se apropiara de la mayoría del excedente social producido siendo centro de la expansión material del sistema, hoy, por primera vez desde su nacimiento, pasan a convivir el principal escenario de dinamización del proceso de acumulación con el campo donde habita la abrumadora mayoría de la población mundial. Junto a la reconfiguración jerárquica que emerge de las nuevas relaciones del $\mathrm{NG}$ con el $\mathrm{SG}$, esa convivencia al interior de este último plantea múltiples realidades y desafíos geoeconómicos y geopolíticos que actúan sobre las bases formativas del capitalismo y sus formas de gobernanza interestatal que han dominado hasta finales del siglo XX.

\section{El surgimiento del Sur Global: ¿hacia una nueva gran divergencia?}

Entendemos por SG al conjunto de regiones y países que conforman la periferia del sistema mundo, es decir, aquellos que no fueron parte de la escena europea del siglo XV y XVI donde emergió el capitalismo. Representa ese inmenso espacio en donde, desde ese momento, no estuvieron radicadas las actividades núcleo de las redes de producción, circulación y valorización de capital, ni han residido allí las agencias estatales que hegemonizaron el sistema interestatal erigido a lo largo de los sucesivos ciclos capitalistas de acumulación (Arrighi, Silver y Brewer, 2003; Arrighi, 2007b). 
En tal sentido, es importante precisar que, con la llegada de los europeos a las costas americanas, a fines del siglo XV, se constituyó por primera vez un sistema con escala planetaria. Hasta ese momento las diferentes regiones del globo habían existido de manera relativamente autónoma entre sí. Pero con el comienzo de la expansión de ultramar se gestó un mercado global con una estructura que opera desigualando las regiones del globo entre sí. Ello configuró un centro sistémico que dio origen a la periferia del sistema mundo, es decir, a todas aquellas regiones del planeta que fueron incorporadas de manera subordinada, en muchos casos forzosa, a la lógica del sistema mundo capitalista (Wallerstein, 2004; Gunder Frank, 1998).

El continente europeo era un espacio geográfico de relativamente poca importancia al tiempo que la división entre las regiones era más bien geográfica/política, antes que económica. Entre los años 1000 y el 1500, las regiones de lo que hoy llamamos SG, representaban el $82 \%$ de la población mundial y el $83 \%$ del ingreso mundial. Durante el período 1500 a 1820 , su participación en el ingreso global decayó hasta el $63 \%$ en favor del NG, principalmente de los países europeos, aunque la gran divergencia vendrá después (Nayyar, 2013).

Gráfico 1. Distribución porcentual del PBI global, NG vs. SG, 1820 a 1950

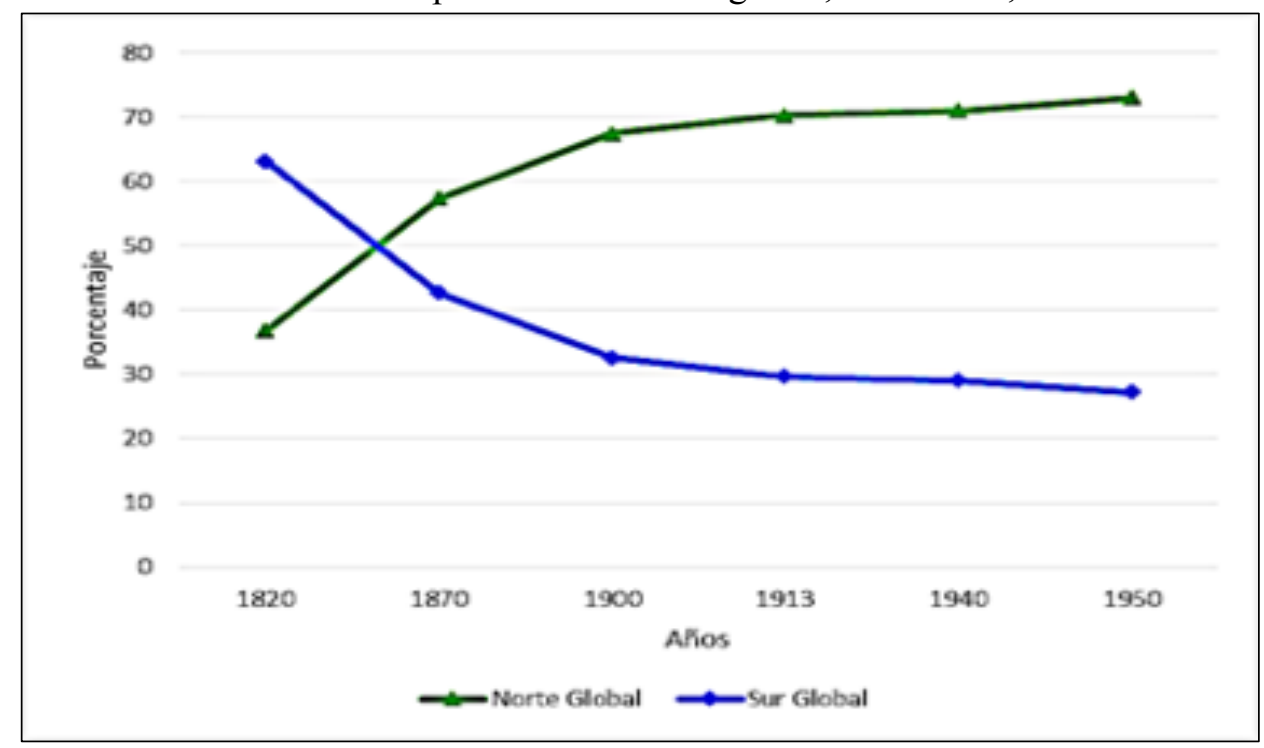

Fuente: Elaboración propia en base a Nayyar (2013).

Entre 1820 y 1950, las diferencias entre el SG y el NG se consolidaron (Gráfico 1). En este período, la participación de Europa en el ingreso global aumentó duplicándose del $37 \%$ al $73 \%$ del total, mientras que el resto del mundo decayó del $63 \%$ al $27 \%$. Estos cambios en el ingreso se dieron sin que se registraran grandes cambios demográficos en ambas regiones del globo. El gran aumento de la productividad del continente europeo inicialmente, y luego de Norteamérica, se debió a la incorporación de la maquina a vapor que permitió incrementar la productividad del trabajo en la industria (Broadberry, Fremdling y Solar, 2014).

La brecha en el ingreso global resulta del ascenso manufacturero de Europa y Norteamérica, es decir del NG, y la decadencia manufacturera en el SG (Gráfico 
2). Esta reversión de la matriz manufacturera del SG implicó la destrucción de su capacidad de generar valor agregado, una pérdida sobre el valor agregado manufacturero, así como un retroceso en su participación en el PBI mundial. A la vez, esos productos fueron reemplazados por los bienes provenientes del NG, con los cuales la industria del SG no podía competir (Bairoch, 1982). Por lo tanto, el SG comenzó un proceso de especialización productiva basada en recursos naturales y bienes primarios.

Gráfico 2. Distribución porcentual de la producción manufacturera a nivel global $(1750-1950)$

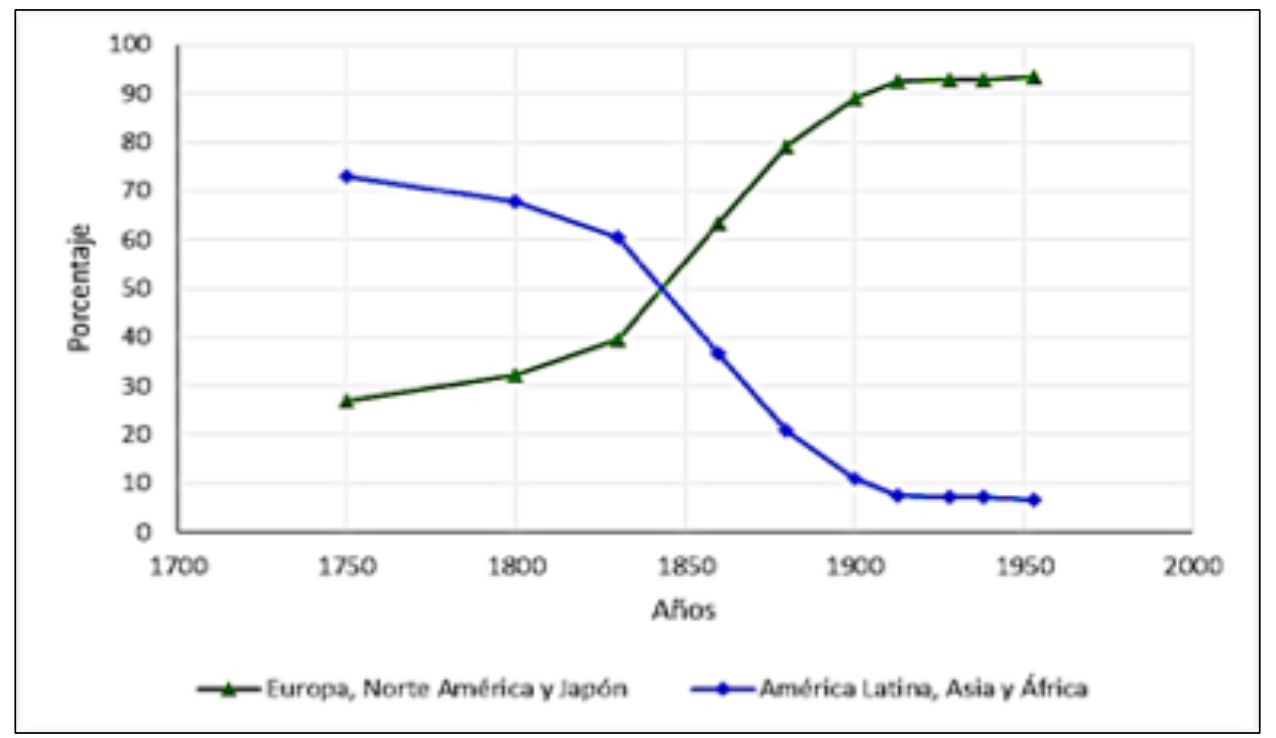

Fuente: Elaboración propia en base a Bairoch (1982).

El Gráfico 3 ilustra el promedio de productos exportados por el "tercer mundo" durante el siglo XIX. Observamos allí que las materias primas y los alimentos representaron dos tercios del total de los productos exportados, contrastando con los bienes manufacturados, que alcanzaron entonces tan solo el 10\% del total exportado.

Esta re-primarización de las economías del SG da cuenta que la especialización productiva entre el Norte industrial y el Sur primario es una realidad relativamente novedosa en el sistema mundo. El resultado fue la concentración de actividades productivas centrales y el control de las mismas por las agencias capitalistas del NG, lo que otorga a esta región una mayor capacidad para retener y acumular los productos del creciente excedente global, mediante el control de los flujos de bienes, servicios y capitales. Por el otro lado, como emergente de un proceso complejo, donde interactúan dinámicas internas regionales y globales (Gellert, 2010), el SG asienta su matriz productiva primaria, y su inserción comercial basada en la exportación de bienes primarios. Ello apareja un núcleo de acumulación débil, subordinado a la demanda externa y con escasa capacidad de retención del excedente en sus territorios y aún menor control del proceso de acumulación (Bairoch y Wright, 1996). 
Gráfico 3. Distribución de exportaciones del Tercer Mundo por producto (promedio período 1815-1914)

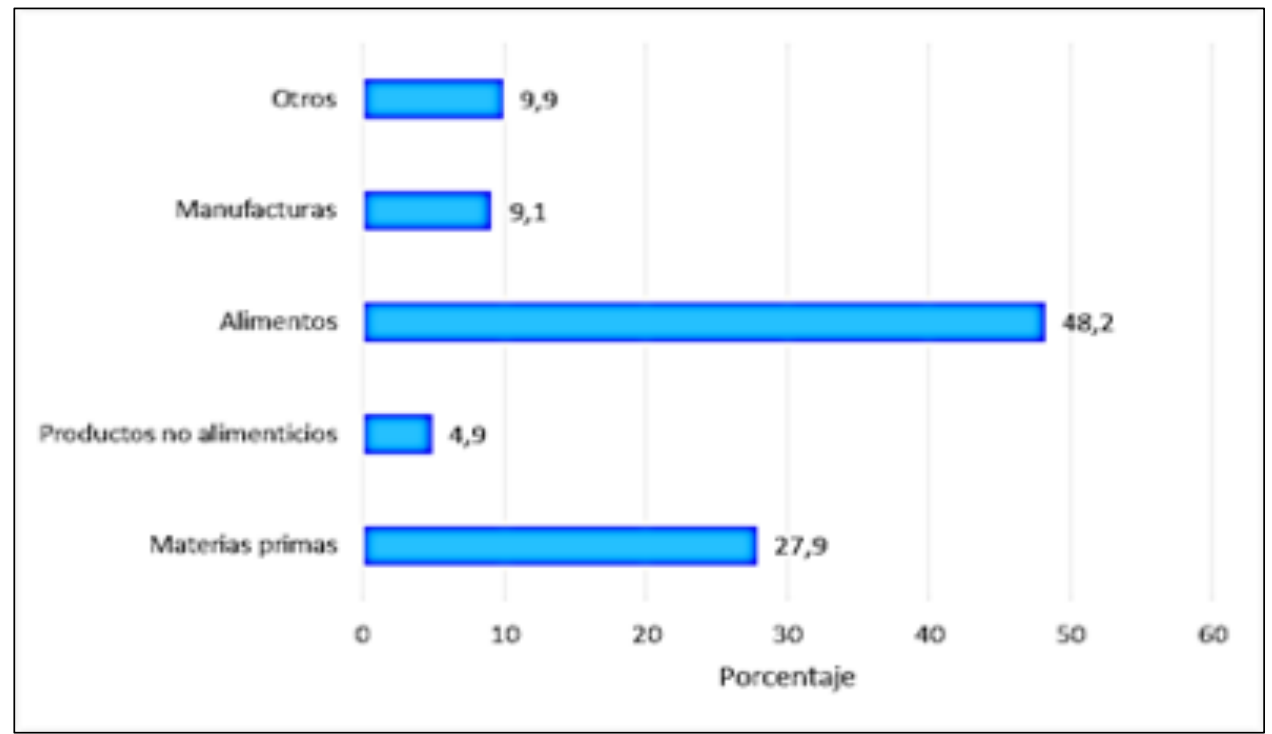

Fuente: Elaboración propia en base a datos de Bairoch (1996).

Gráfico 4. PBI per cápita promedio países NG y SG (en precio dólar corriente)

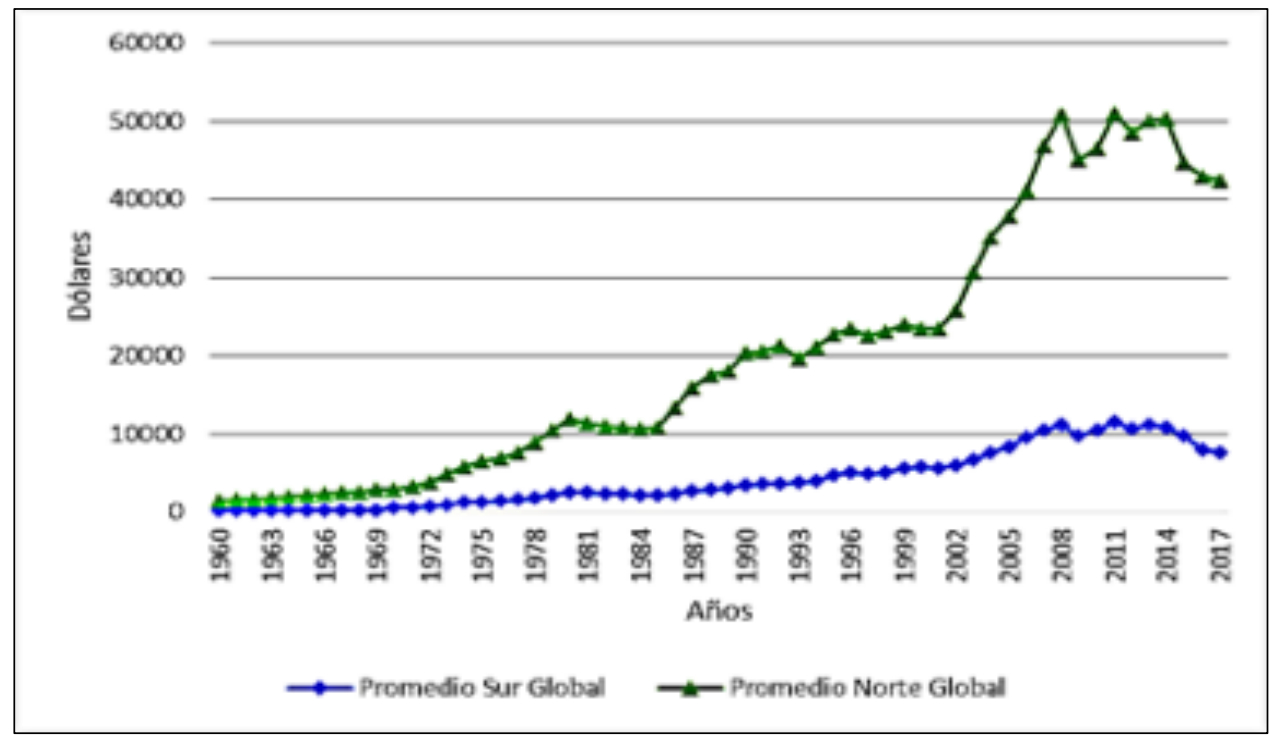

Fuente: Elaboración propia en base a Banco Mundial y UNCTAD.

Ahora bien, a partir de la década de 1950, el SG se constituye en el área más dinámica del sistema mundo a nivel de los flujos que sostienen el proceso de acumulación, proyectando un crecimiento sostenido. En tal contexto, y particularmente a partir de los años 60s, la participación del SG en el total del PBI mundial creció de 
manera sostenida. Ello se refleja en sus mayores tasas de crecimiento comparado. Mientras que las diferencias fueron moderadas durante la posguerra, se acentuaron después de la crisis de los 70s, y dieron un salto de envergadura con el cambio de milenio, debido al ingreso de China como actor de peso en el comercio mundial.

Si el análisis de la estratificación y cambios en el SM continúa siendo realizado a través del PBI per cápita — como lo han hecho los enfoques de la TSM para estratificar a los países y regiones (Pasciuti y Payne, 2017)— vemos que el NG lleva la delantera y que tiende a ampliar la brecha (Gráfico 4).

Sin embargo, si dislocamos el elemento demográfico del comportamiento del PBI total (Gráfico 5), se percibe con claridad la ralentización del crecimiento del NG - acompañado de desindustrialización-y el sostenido crecimiento del SG desde la posguerra, pero particularmente en lo que va del nuevo siglo. Esto permitió que prácticamente se equipare el volumen productivo entre ambas regiones, algo inédito desde la consolidación del capitalismo europeo.

Gráfico 5. Distribución porcentual del PBI mundial entre el Norte y el Sur

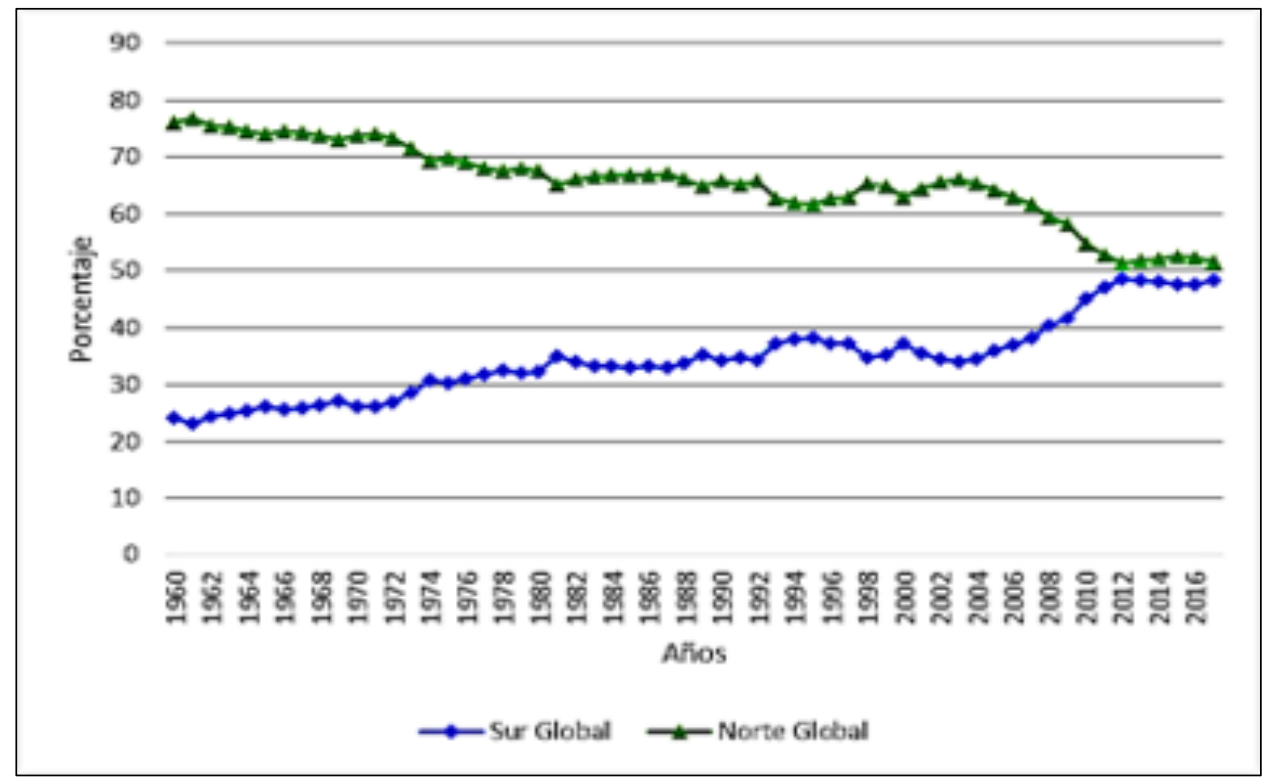

Fuente: Elaboración propia en base a Banco Mundial.

Del análisis estadístico se desprende que para los años seleccionados (1970, 1990 y 2018) en los Gráficos 6 y 7 las variaciones en la mediana del PBI para el SG son significativamente mayores, lo que da sustento al argumento de una convergencia económica de esta macro región respecto del NG. En este sentido, resaltamos que, como se desprende de la observación del gráfico de cajas, a pesar del crecimiento sostenido del PBI durante el período seleccionado el SG presenta una mayor heterogeneidad interna. Esto se ve reflejado en la dispersión interna de los valores correspondientes a los países miembros. Por lo tanto, confirmamos nuestra afirmación inicial respecto a que no todas las regiones, ni todos los países contribuyen en la misma proporción en el incremento PBI del SG. 
Gráficos 6 y 7. Distribución del PBI al interior de las macro-regiones

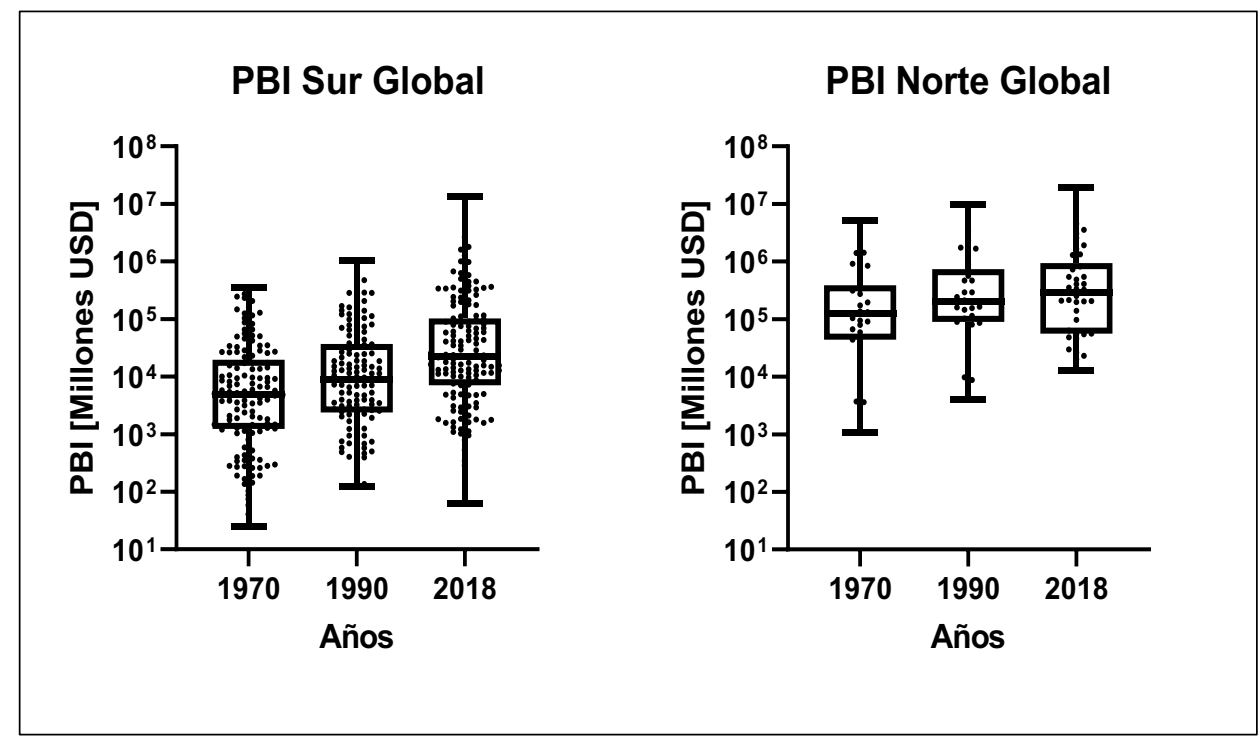

Fuente: Elaboración propia en base a datos de UNCTAD.

Por su parte el NG no presenta una variación significativamente mayor en la mediana de su PBI en la comparación entre los años seleccionados $(1970,1990$ y 2018), dando sustento a las hipótesis que sostienen la mayor capacidad de apropiación y retención del excedente global producido por parte del NG, principalmente a través de mecanismos de tipo financiero y por el control sobre las redes de producción global por parte de sus ETS. Esto sucede, en el macro de una etapa de declive económico relativo marcada por la expansión financiera de EE UU. También se observa que el NG presenta una mayor homogeneidad interna respecto a la contribución de los países miembros en términos del PBI global.

\section{De los flujos de producción a los flujos de intercambio: dinámica comparada del SG y su entrelazamiento interno}

El crecimiento del producto del SG y su convergencia con el NG generó un aumento de los flujos de intercambio, representados por las inversiones externas directas (IED) y del comercio con origen interno al SG. En el Gráfico 8 puede observarse el crecimiento del SG en el comercio mundial. En sesenta años, la participación del SG en el comercio mundial creció un $20 \%$, desde el $30 \%$ al $50 \%$. Es decir que, al igual que el producto, el comercio del SG observa un inédito desarrollo que iguala su participación a la del NG en proporción al total mundial (Bernhardt, 2016).

Este proceso, junto a un incremento de los vínculos Sur-Sur, da cuenta del entrelazamiento del SG como unidad económica, contrastante con la ralentización de los vínculos Norte-Sur y Sur-Norte. Como se observa en el Gráfico 9, desde el último quinquenio del siglo XX hasta el final del tercer quinquenio del siglo XXI, las exportaciones Norte-Norte, Norte-Sur y Sur-Norte han tenido un crecimiento mucho más moderado que las que representan los vínculos Sur-Sur. 
Grafico 8. Evolución porcentual de la participación en el comercio mundial

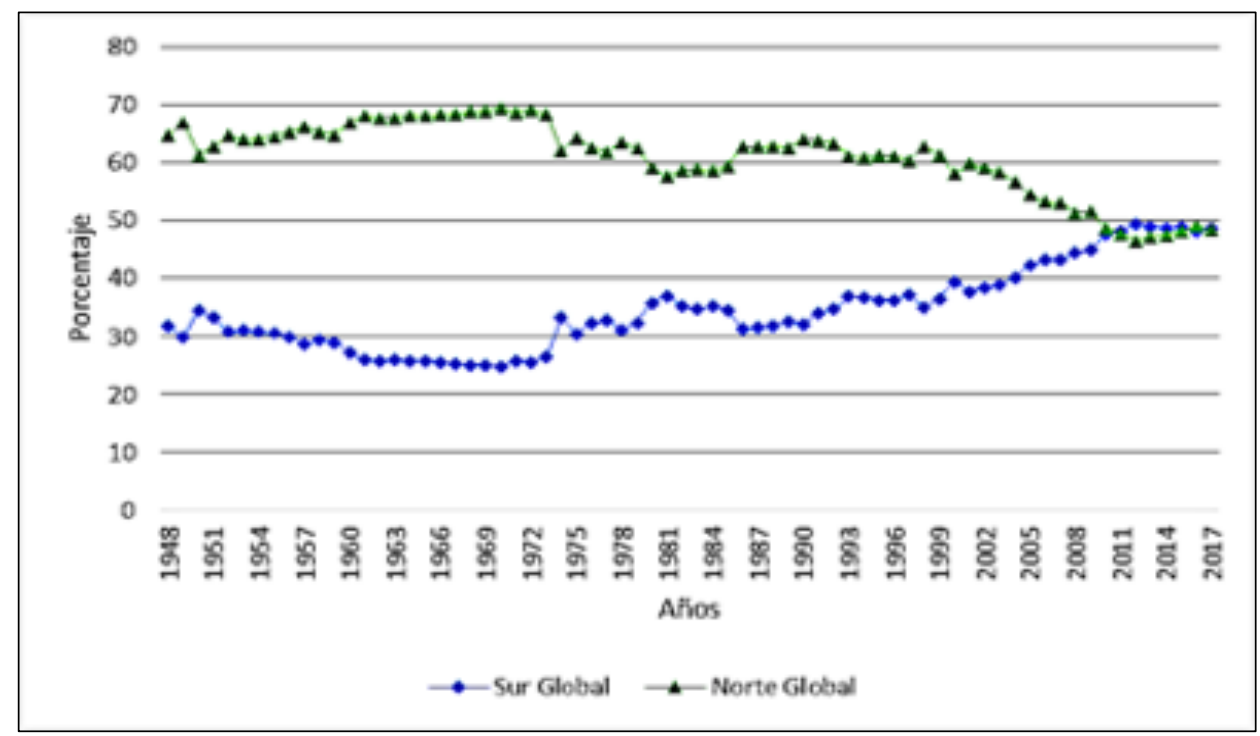

Fuente: Elaboración propia en base datos UNCTAD.

Grafico 9. Evolución de las exportaciones por destino, grandes áreas globales

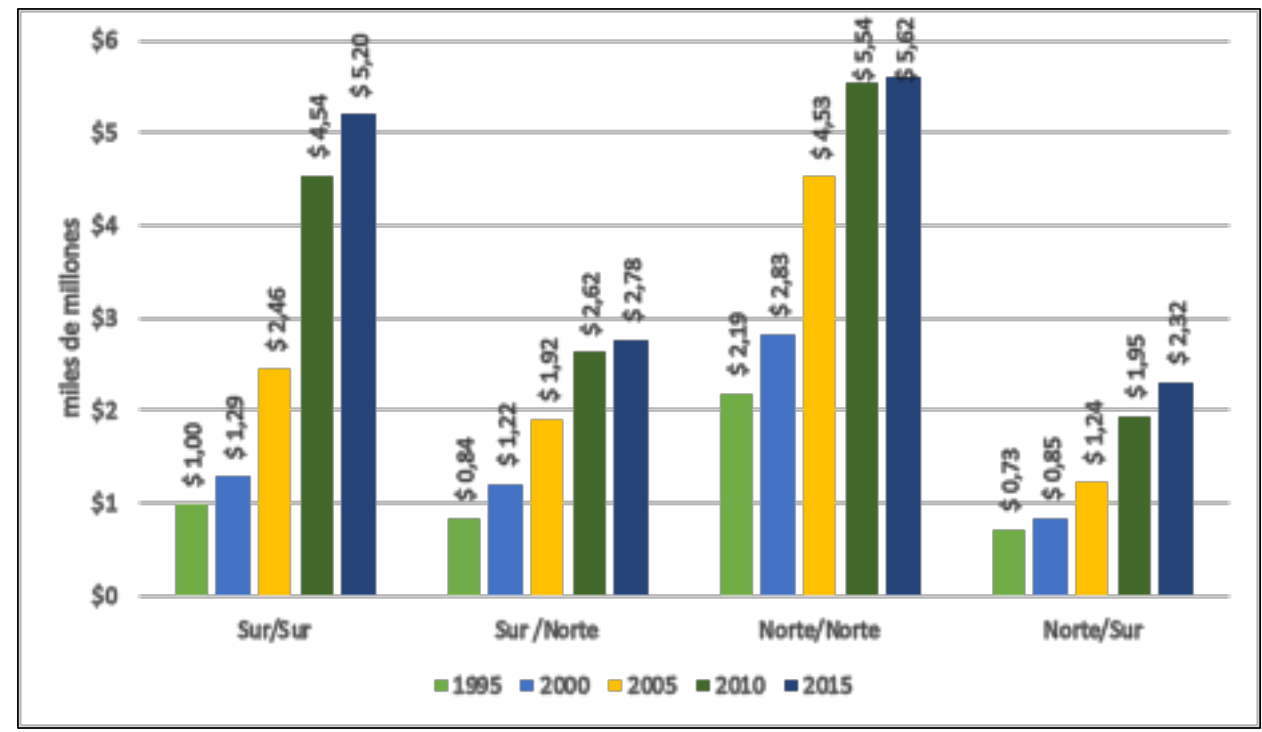

Fuente: Elaboración propia en base a datos de la UNCTAD.

Siguiendo con el análisis, las exportaciones al interior del SG no sólo han igualado el intercambio al interior del NG, lo cual ya es un hecho sin precedentes, sino que también ya casi duplican aquellas que presentan la relación comercial norte/sur, así como las sur/norte consideradas, hasta hace muy poco, como las estructurantes del comercio mundial. El comercio desigual es señalado como uno de los 
mecanismos que explican el proceso de desigualación entre las regiones del mundo. En ese tipo de intercambio, el NG se veía beneficiado por una creciente alza de los costos de los productos manufacturados frente a un disminución constante de los productos primarios. Por lo que la división entre Norte y Sur se igualaba a países industriales y países no industriales. Sin embargo, los datos actuales parecen demostrar que el intercambio al interior del SM parece girar en torno a dos polos bien diferenciados - de magnitudes similares - mientras que los intercambios entre ambos espacios son prácticamente la mitad de aquellos que estructuran las relaciones N-N y S-S. Este cambio en los flujos comerciales, con preponderancia de los intercambios en el SG, marca un hecho inédito en la configuración de la economía mundo que resignifica a los actores dentro de la relación centro-periferia y abre interrogantes sobre la actual jerarquía (Arrighi, Silver y Brewer, 2003).

En cuanto a la IED, observamos que a partir de la década de los 70s el SG se convierte en un espacio de atracción para la misma. Este fenómeno es, en parte, el resultado de la estrategia de offshoring de los capitales del NG como una fase de la reconfiguración del sistema capitalista y de su estrategia para superar la crisis. Mediante este proceso, la producción se descentralizó y se globalizó, relocalizando aquellos eslabones de la cadena de valor relacionados al uso intensivo de mano de obra en la periferia, particularmente en el sudeste asiático (Santarcángelo, Schteingart y Porta, 2017). La regulación laxa del mundo del trabajo en la periferia y el bajo costo salarial asociado a ello posibilitó a las ETS reducir costos y multiplicar sus excedentes. Esto, sumado a Estados capaces de disciplinar al mundo del trabajo, fueron estímulos importantes para que el capital trasnacional decidiera radicarse en los países del SG (Suwandi, Jonna y Foster, 2019).

Gráfico 10: Recepción de inversión extranjera directa, NG y SG (porcentajes)

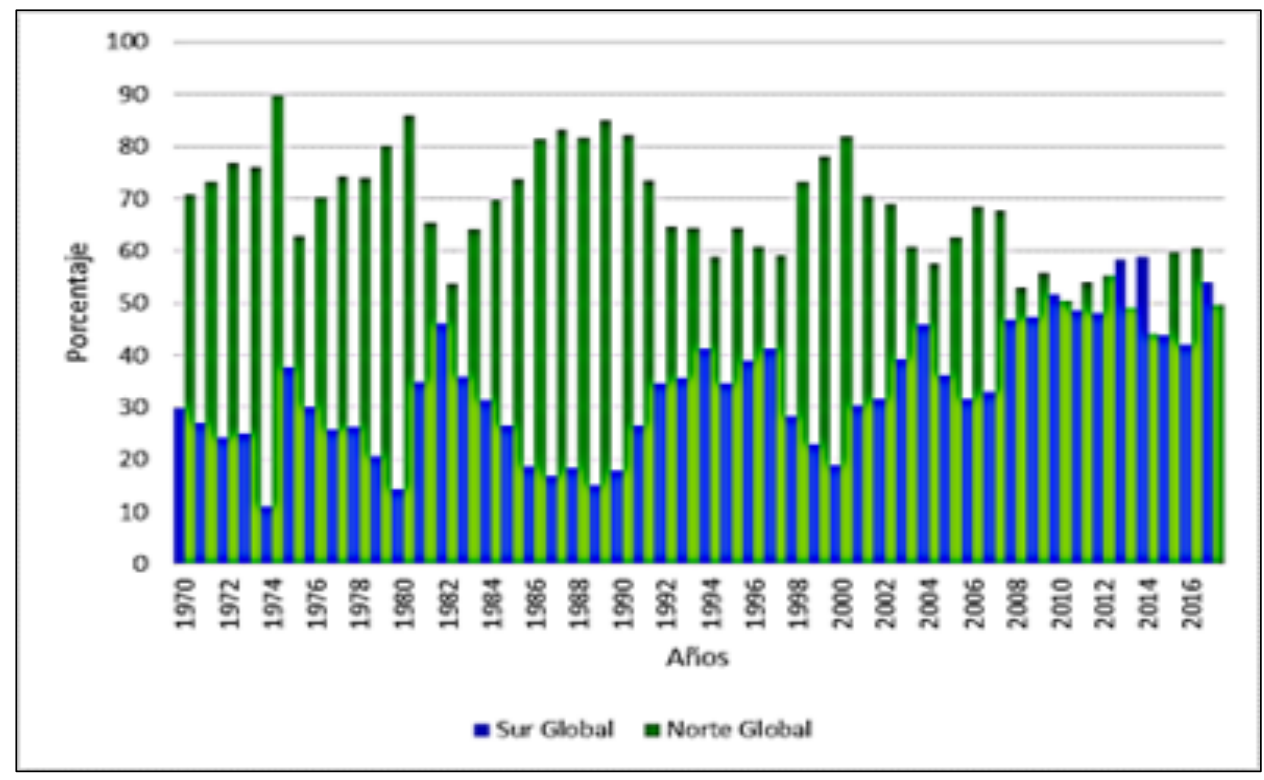

Fuente: Elaboración propia en base a datos de la UNCTAD. 
Como se observa en el Gráfico 10, mientras que la recepción de la IED en el SG en los años 70s alcanzaba tan solo el 30\% de la inversión mundial, para 2017 esta región concentra el 49,8\%. Aun con sus altibajos a lo largo de los años 80 s y 90 s, la IED por parte del SG se vuelve más sostenida.

Gráfico 11. Exportación de capitales, Inversión extranjera directa, NG y SG

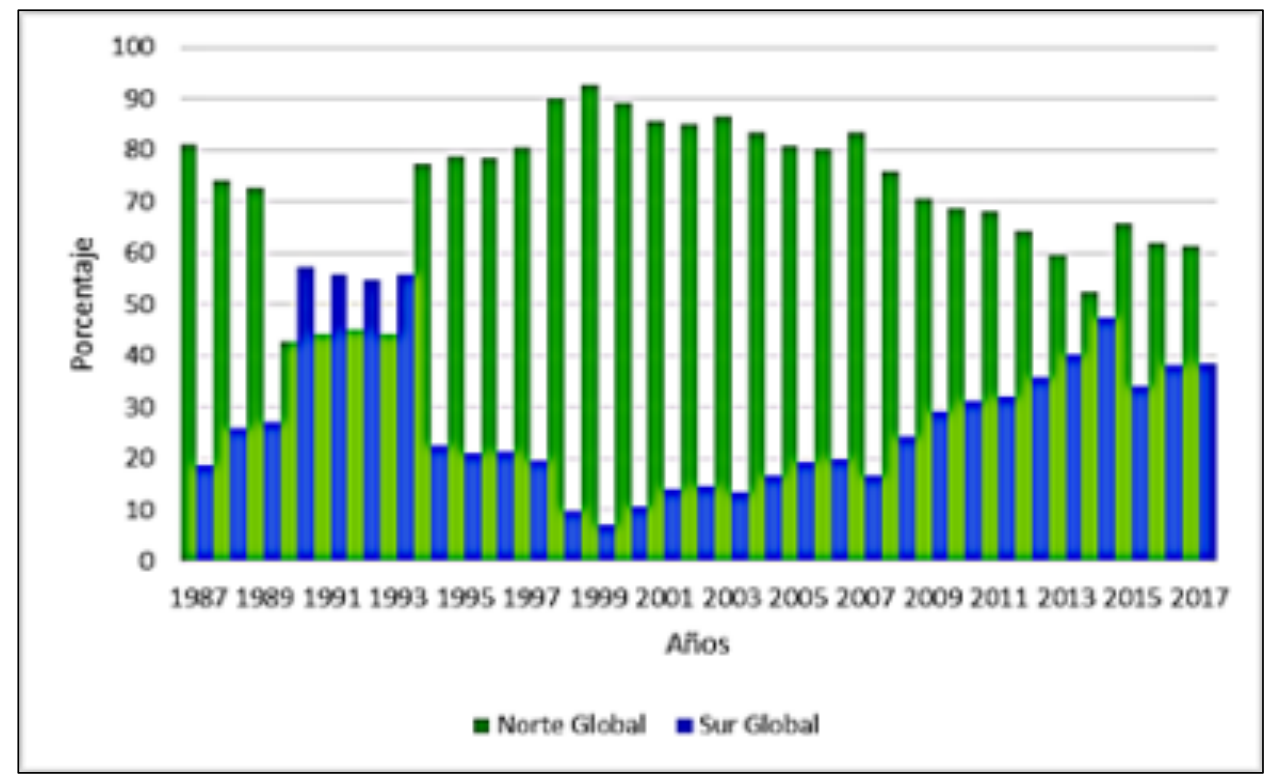

Fuente: Elaboración propia en base datos de la UNCTAD.

Cierto es que aunque buena parte de esa inversión contribuyó a incrementar el porcentaje de manufacturas en el SG, producto de una fuerte descentralización de procesos de producción y ensamblado a través de lógicas offshore (Milberg y Winkler, 2009), la mayor parte de ella no cuestionaba el control del excedente en manos de las ETS del NG, al retener éstas los eslabones estratégicos de las cadenas globales de valor (Fernández, 2015; Kaplinsky, 2016). No obstante, las bases de industrialización combinadas con una autonomía estatal - geopolíticamente concedida - particularmente en el Este asiático, y su continuidad a partir del proceso de acumulación con industrialización de China, viabilizaron un control creciente de esas cadenas por parte de actores locales. Ello no sólo permitió acrecentar su capacidad de retener excedentes en sus espacios geográficos, a partir de up-grades tecnológicos, sino también desplegar un progresivo proceso de emisión de inversiones dentro del SG. Como se observa en el Gráfico 11, estas inversiones experimentaron un crecimiento constante a lo largo de todo el nuevo siglo (UNCTAD, 2015b).

\section{El Sur Global manufacturero: de la desindustrialización a la reindustrialización}

Como hemos señalado, este incremento de los flujos comerciales y financieros estuvo asociado a un crecimiento visible de la producción manufacturera en el SG. 
Ello fue resultado no solo de la relocalización productiva desde el centro hacia la periferia - luego de la maduración de los procesos de maduración en el centro y la necesidad de estos espacios de encontrar nichos de rentabilidad y menor conflictividad-, sino también de los procesos de industrialización conformados en torno a plataformas nacionales.

Este último proceso constituyó un elemento central para conformar una dinámica de interacción con base industrial al interior del SG, en donde resaltan no solo los aspectos cuantitativos sino también aquellos de orden cualitativo. Estos últimos afectan las condiciones de acumulación a largo plazo, rompiendo condiciones de subordinación o recreando nuevas formas en las redes económicas globales.

\section{A) Dimensiones cuantitativas}

Efectivamente, desde la posguerra, el SG se fue transformando en el centro fundamental de la producción manufacturera mundial (Gráfico 12). Su participación creció constantemente, saltando desde un 14,8\% a inicios de la década del 70 hasta llegar a un 49\% a inicios de 2017 (Nayyar, 2013). Al mostrar una reversión de la tendencia desindustrializadora anterior, el SG adquiere un rol central en la formación del producto industrial global.

Grafico 12. Participación de las macroregiones en la producción manufacturera a nivel global 1970-2017 (en porcentajes)

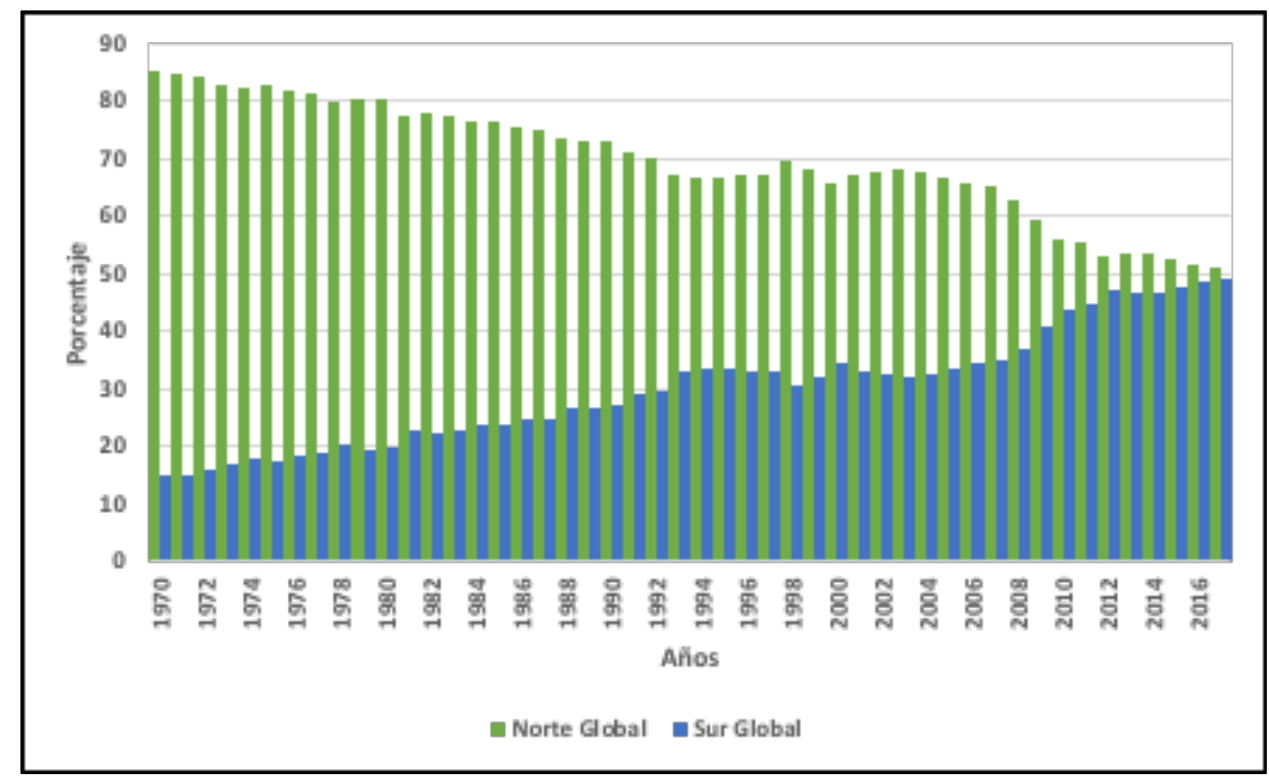

Fuente: Elaboración propia en base a UNCTAD.

La exportación manufacturera aumentó al ritmo del proceso de industrialización. En este caso, el SG pasó desde un $6,4 \%$ en los años 60 s a un $29,3 \%$ hacia inicios del nuevo siglo, hasta llegar a trepar a $40,1 \%$ tan solo una década después. Finalmente, en el plano intraregional-nacional, las economías del SG, miradas en su conjunto, mostraron desde los 90s un crecimiento constante del Valor Agregado 
industrial en sus respectivos PBI, en contraposición con el progresivo decrecimiento en los países centrales.

En muchos casos, estos procesos de industrialización han reflejado una "ilusión del desarrollo" (Arrighi, 1990), producto del alojamiento en el SG de actividades manufactureras que no refieren al control de funciones estratégicas en las redes económicas globales, lo que impide revertir la captura concentrada de los ingresos en el NG, dando como resultado economías industriales sin un aumento de los ingresos per cápita (Arrighi, Silver y Brewer, 2003). Es decir que, el aumento de la capacidad manufacturera no se tradujo necesariamente en mayor acaparamiento del excedente global. Tampoco la industrialización se tradujo en la modernización de sus estructuras económicas y sociales, ni en la homogeneización de sus estructuras productivas (Reifer, 2011).

Graficos 13 y 14. Valor agregado manufacturero sobre el PBI por país

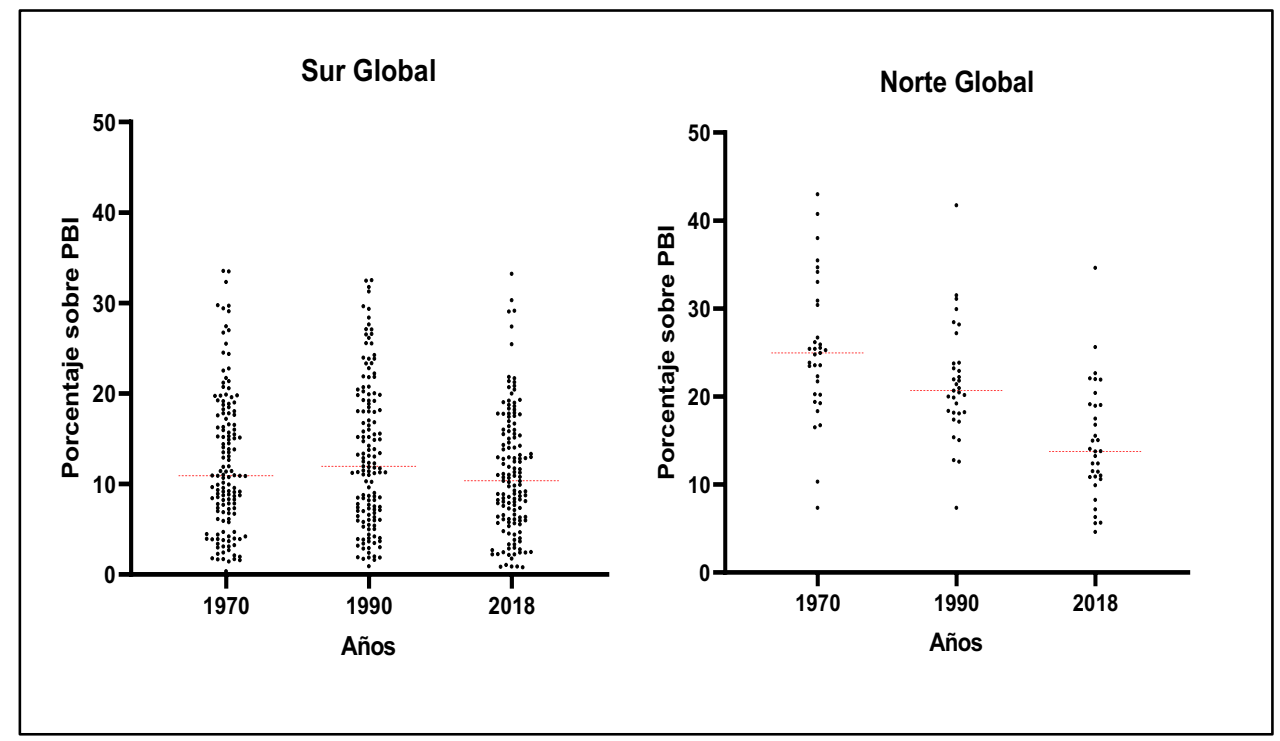

Fuente: Elaboración propia en base a datos de UNCTAD.

Para el caso del SG se observa que, una vez más, el proceso de ascenso del SG muestra su heterogeneidad interna característica. Para los años seleccionados en los Gráficos 13 y 14 el análisis estadístico muestra una variación menor entre las medianas al interior del SG respecto del porcentaje que representan las manufacturas al interior de cada país miembro. Si bien, una parte mayoritaria de los países se concentran en torno a valores próximos a la mediana, se destaca un conjunto de países que sobresale. Esta característica heterogénea del comportamiento de las manufacturas al interior del SG es parte de un proceso en el cual la región del sudeste asiático se destaca en su rol como productor de manufacturas, a la vez que fue conformando un sistema de relevos regionales por los cuales la producción de manufacturas fue migrando de país en país a medida que fueron variando los costos de producción y los salarios. Al año 2018, el sudeste asiático y en particular China, representan el centro del auge manufacturero del SG y el más importante de la economía mundo. 
En el caso del NG, se observa una variación mayor entre las medianas para los años seleccionados, confirmando el retroceso manufacturero de las economías desarrolladas y su orientación hacia los servicios especializados, y en particular a otras formas de valorización no materiales.

\section{B) Dimensiones cualitativas}

No obstante, el ascenso manufacturero del SG da cuenta progresivamente de un conjunto de aspectos de orden estructural que posibilitan el fortalecimiento del control endógeno del proceso de industrialización en particular, y del proceso de acumulación en general.

Grafico 15. Cambios en la composición de la canasta de exportables de los países en vías de desarrollo (en porcentajes)

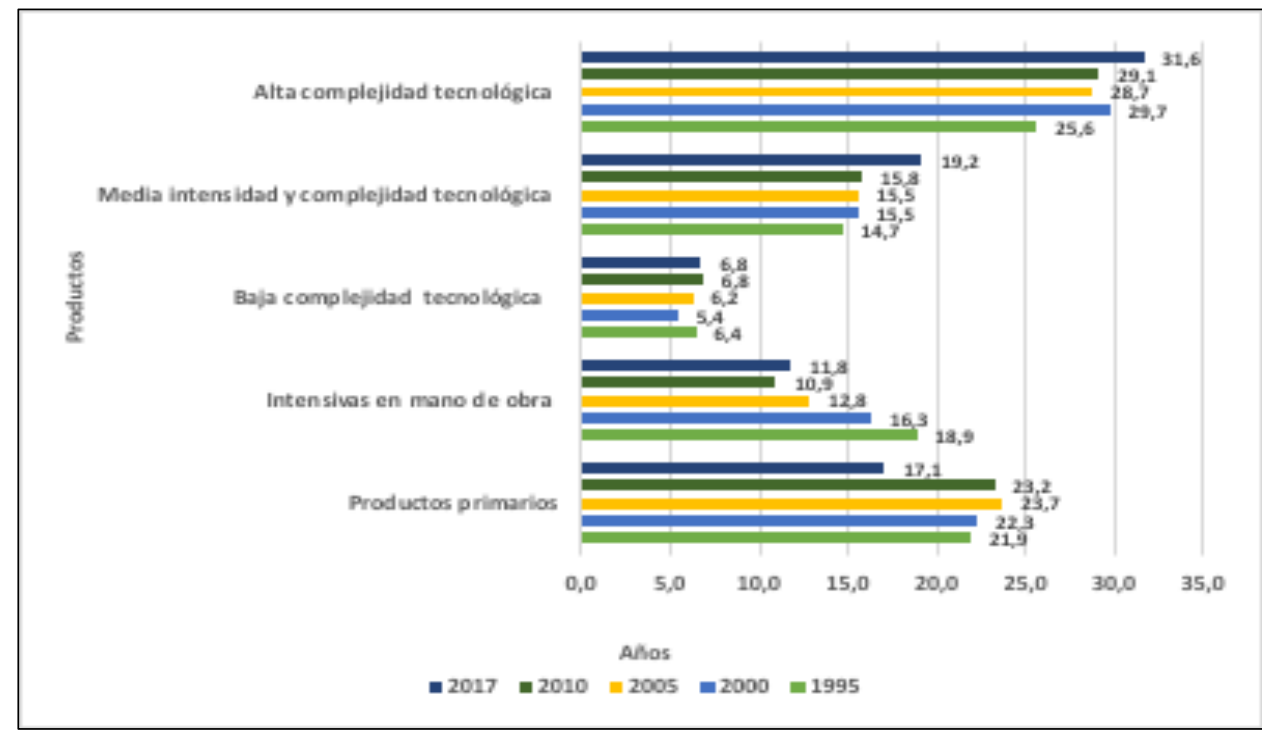

Fuente: Elaboración propia en base a UNCTAD.

El primer aspecto a resaltar es el contenido de la canasta de exportables (Gráfico 15), que presenta una mayor preponderancia de manufacturas con mayor grado de complejidad tecnológica en detrimento de otras exportaciones sustentadas en materias primas o bienes industriales de escasa complejidad. Mientras que las exportaciones tecnológicas representaban hacia los años 80 tan solo el 8,9\%, hacia finales del siglo XX representaban más del 43,9\%, el 46,3\% en la primera década del siglo XXI y el 50,8\% en 2017.

\section{Dinamización del proceso de acumulación bajo la lógica de funcionamiento en redes globales}

Los cambios en el contenido tecnológico de las exportaciones son el resultado de la dinamización del proceso de acumulación a través del aumento constante en la 
creación de conocimiento aplicado y de recursos calificados para su generación. Esto podemos observarlo en el comportamiento comparado respecto de la creciente inversión en $\mathrm{I}+\mathrm{D}$ desde la década de los 80 en adelante y la consecuente creación de patentes tecnológicas.

Si nos detenemos en el Gráfico 16 veremos que desde finales del siglo XX el SG ha aumentado considerablemente su participación en la inversión global en I+D, desde tan sólo el 17\% en 1998 al 41,3\% en el año 2016. Demuestra un salto cuantitativo-cualitativo muy fuerte en un escaso margen temporal. Ese aumento en la $\mathrm{I}+\mathrm{D}$ forma parte de una estrategia de desarrollo estatal tendiente a generar procesos de cualificación de sus empresas locales, centrada en la coproducción y transferencia público privado de ciencia y tecnología. Con ello, el objetivo es poder ascender en los eslabones de las cadenas productivas de valor desde procesos de manufactura y ensamblado, que concentran menos valor, hacia los de diseño y marketing, espacios donde se concentra el poder de control de las redes de acumulación global (Gereffi, Humphrey, Sturgeon, Kaplinsky y Raphael, 2001). Sin embargo, si nos detenemos en el aporte de las regiones al interior del SG, observamos que el Este asiático consolida su liderazgo tecnológico productivo y se consolida como el centro dinamizador de la producción e innovación lo que le permite competir crecientes porciones del mercado mundial con los monopolios de los países más avanzados del NG.

Grafico 16. Inversión en I+D global, Norte y Sur global

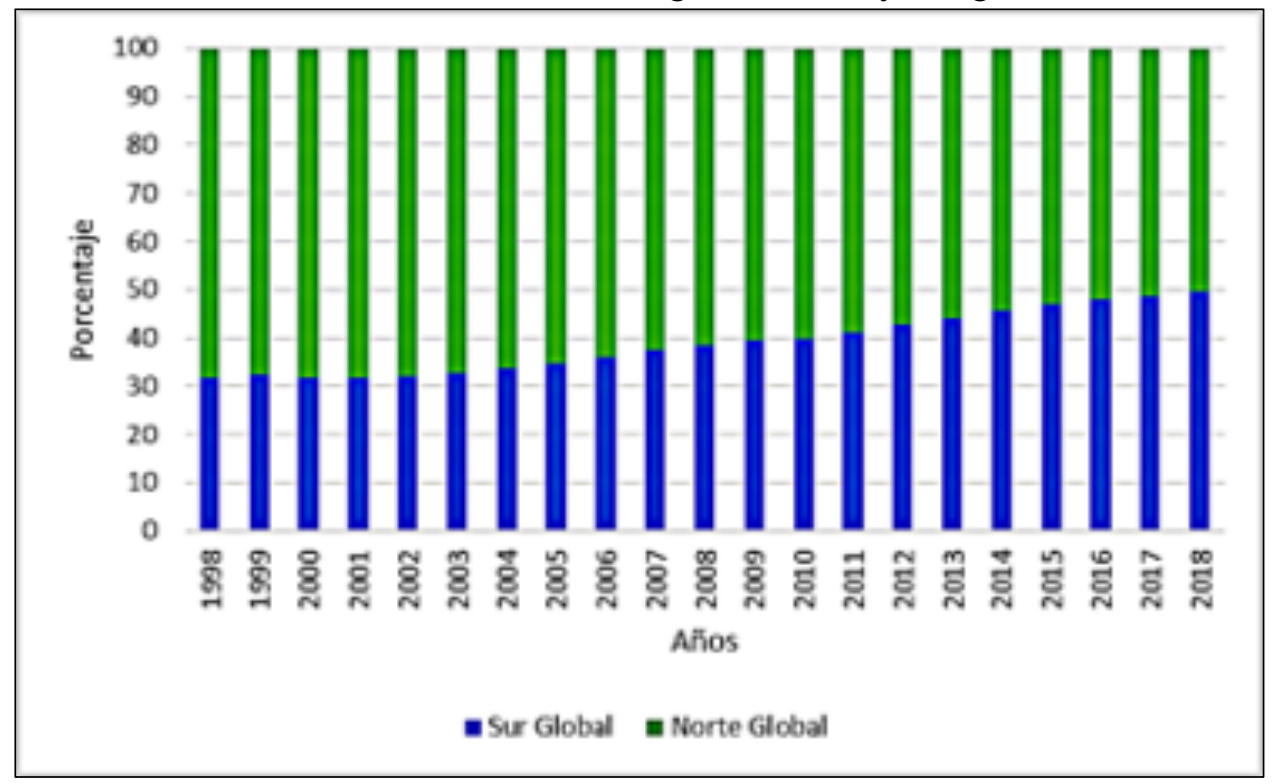

Fuente: Elaboración propia en base a UNESCO.

Dicha estrategia coloca a los Estados-nación en el centro del proceso de acumulación de capital y en la generación de espacios de autonomía capaces de permitir el desarrollo de los capitales locales. Aun con la enorme divergencia y heterogeneidad en su interior, el SG invierte cifras cercanas al NG en I+D (UNESCO, 2017). 
El retorno de estas inversiones en $\mathrm{I}+\mathrm{D}$ y su traducción en procesos aplicados ha contribuido al incremento de patentamientos en los países del SG. Esto aparece como un indicador central del proceso de cualificación de la producción, debido a que el acceso y control de la información es un elemento central en el proceso de acumulación y reproducción del capital. Como se observa en el Gráfico 17, a finales del siglo XX el NG concentraba el $60 \%$ de los patentamientos concedidos, pero el año 2017 este número se invierte pasando a ser el SG el espacio que concentra el mayor número de patentes. Por primera vez desde la revolución industrial, la vanguardia del desarrollo tecnológico se concentra en un espacio no occidental.

Grafico 17. Total patentes concedidas, recuento total, Norte Global $v s$. Sur Global, 1997-2017

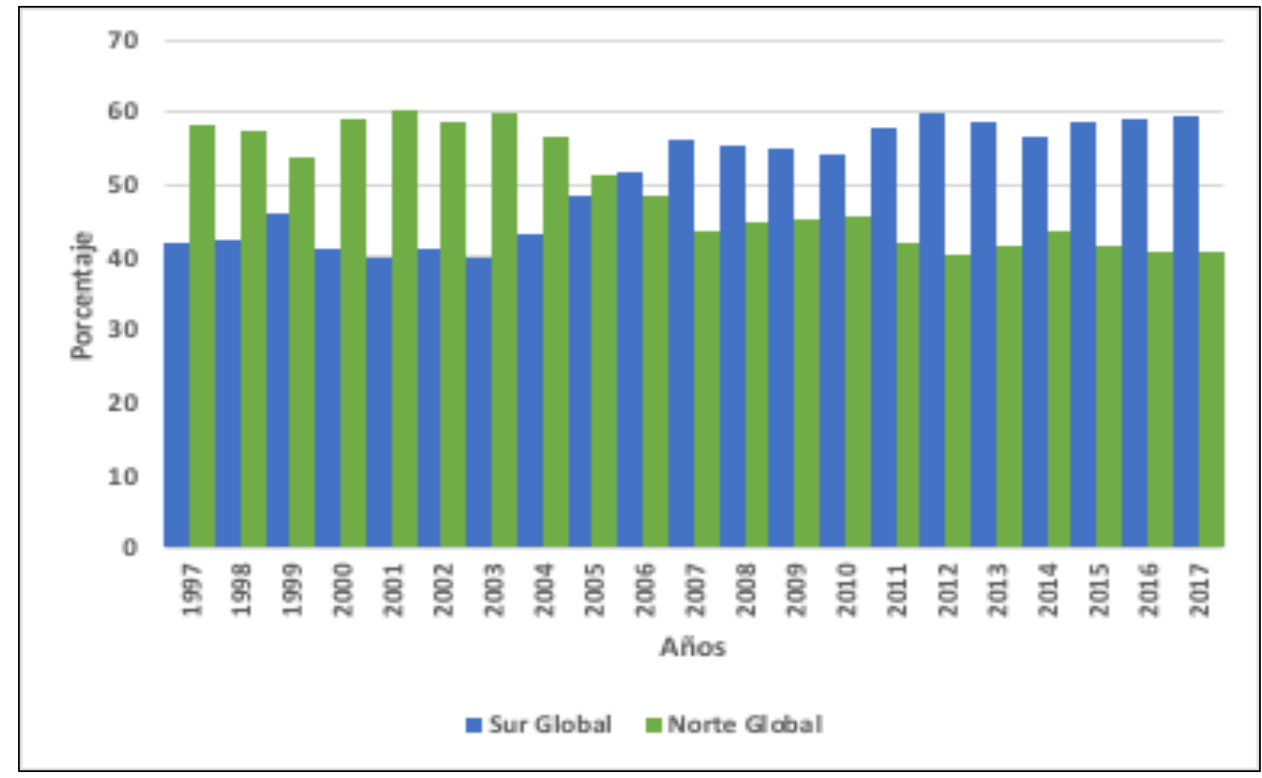

Fuente: Elaboración propia en base a datos de WIPO.

\section{Control creciente a través de los actores trasnacionales}

Como señalamos, el comportamiento a nivel de flujos que motorizan el crecimiento económico del SG, el comercio, la IED y el crecimiento del PBI manufacturero, y el acompañamiento de ello por la dinamización de los procesos de innovación y aprendizaje, han logrado sostenibilidad por la creciente presencia de actores trasnacionales en esos espacios. Estos operan con sus Estados nacionales en el apuntalamiento de espacios de autonomía para la generación, retención y reinversión del excedente global. Como se observa en el Gráfico 18, vemos el notable crecimiento que ha tenido lugar a lo largo de las casi dos décadas del presente siglo en la cantidad de ETS cuyas casas centrales se localizan en el SG.

La distribución territorial de las 500 empresas más importantes en el mundo se ha modificado sustancialmente en tan sólo los últimos 20 años. Para 1996, el $66,8 \%$ se encontraban radicadas en países del NG. Tenían un claro predominio los 
monopolios de origen estadounidense, seguidos por Japón, Gran Bretaña, Alemania y Francia. Esto constituye un reflejo del control que ejercían estos espacios sobre la acumulación y circulación del capital a nivel global. Sin embargo, a partir del cambio de siglo, observamos una creciente presencia de empresas del SG, las que, bajo el claro protagonismo asiático, para el año 2018 las mismas representan el 43,8\%. Inicialmente motorizado por las empresas de origen japonés, con el cambio de siglo se produjo un relevo por parte de los conglomerados estatales chinos.

Gráfico 18. Distribución de las 500 trasnacionales, Norte y Sur, 1996-2018

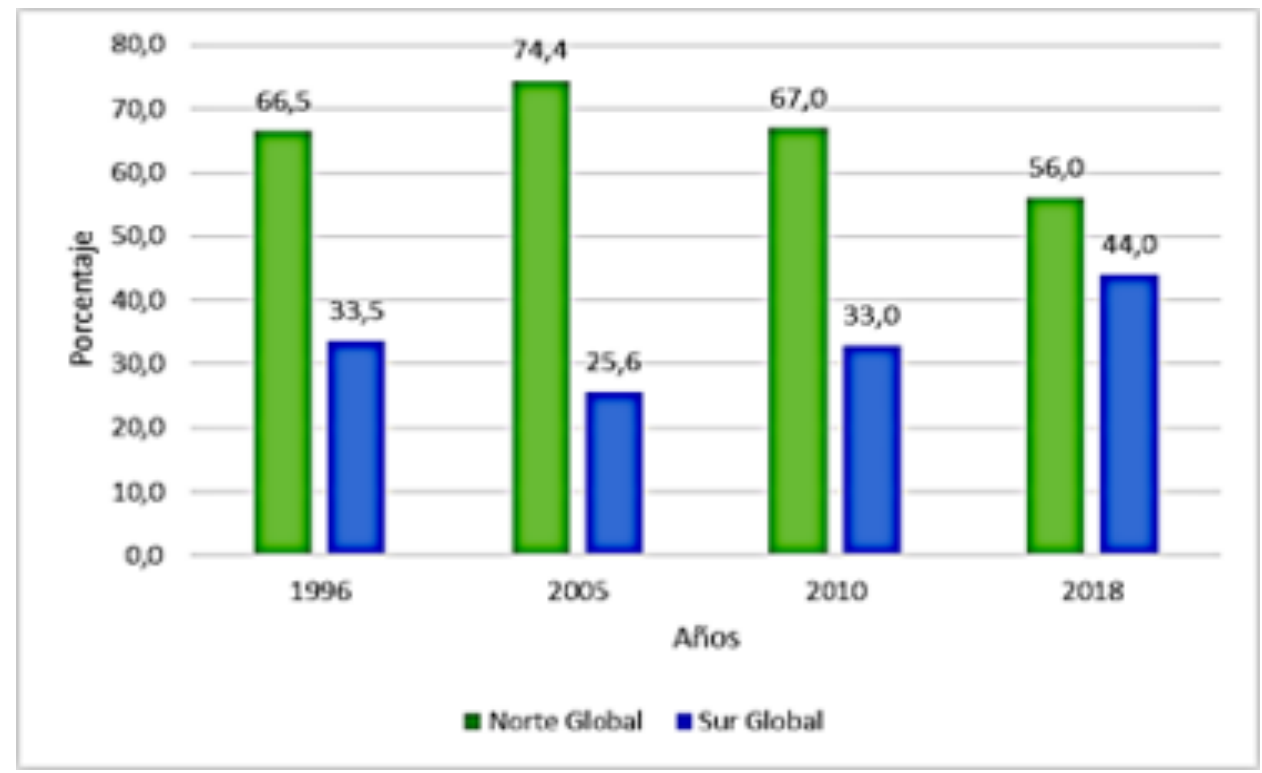

Fuente: Elaboración propia en base a Ranking Forbes Global 500.

En 1996, China contaba tan solo con 3 empresas dentro del ranking. Actualmente, cuenta con 112, lo que grafica el avance de las ETS de este país en los nodos de control de las CVG y su papel central dentro del SG. Como se observa en el Gráfico 19, ese ascenso de las ETS del este asiático, desde el que se potencian los ya analizados vínculos de intercambio e inversión Sur-Sur, contrasta con el retroceso de las empresas europeas y estadounidenses. Sin ser estrepitosa, esa caída refleja la consolidación del SG como espacio de control de funciones estratégicas en las redes económicas globales. Alejando la visión de este espacio como mero receptor de procesos productivos controlados desde el centro y dando cuenta de su capacidad de acaparar mayores porciones del excedente global en sus espacios nacionales y macro-regionales.

En el marco de la geopolítica de la Guerra Fría, el Este Asiático fue consolidando su estrategia de desarrollo orientada por las exportaciones, basadas en un creciente peso de las manufacturas, las inversiones extranjeras directas orientadas hacia la producción y la transferencia de tecnología bajo la dirección de Estadosnación con capacidad de respuesta a los desafíos que les presentaba la estrategia de crecimiento y desarrollo encarada. Esto se tradujo en un mayor dinamismo industrial motorizado por la inversión pública en $\mathrm{I}+\mathrm{D}$, lo que permitió a sus empresas 
locales posicionarse en eslabones de comando al interior de las cadenas globales de valor.

Gráfico 19. Regiones con mayor cantidad de empresas entre las 500 más grandes (1996-2018)

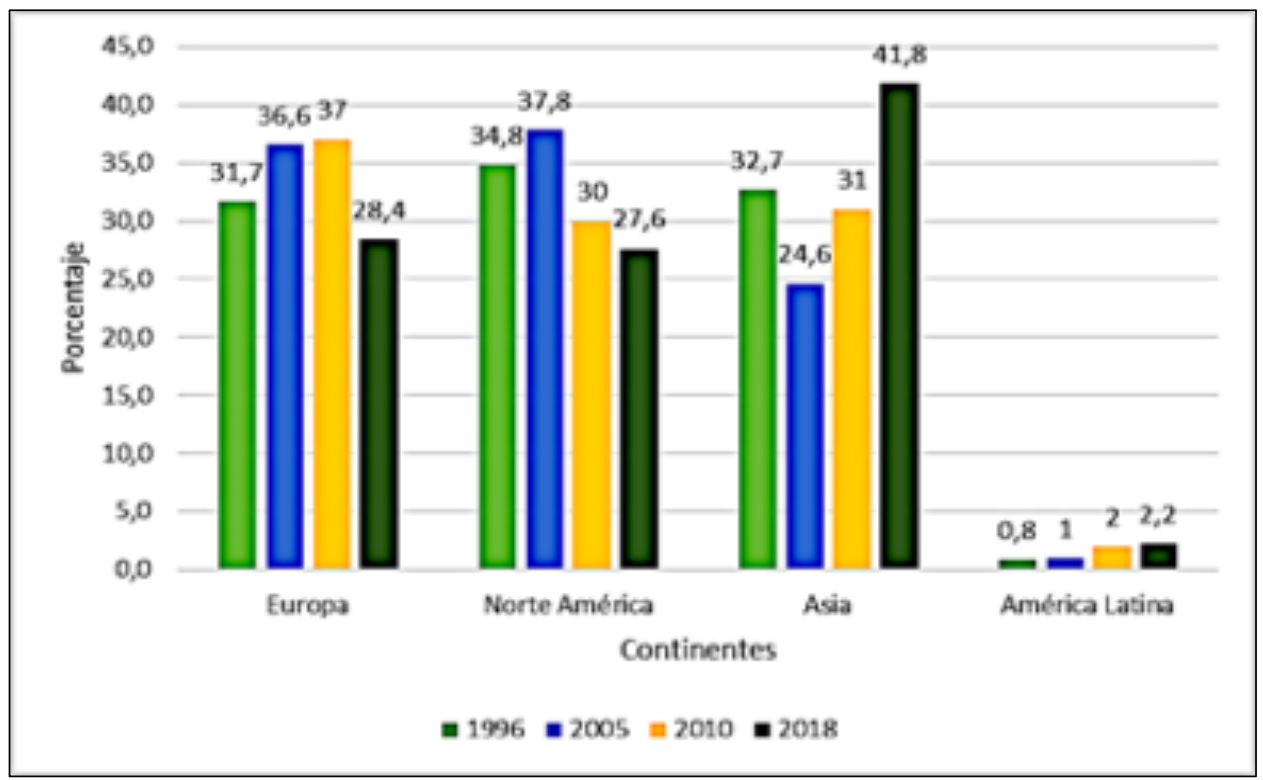

Fuente: Elaboración en base a Ranking Forbes Global 500.

Esta combinación particular de condiciones geopolíticas sistémicas y dinámicas internas con capacidad de respuestas fueron únicas del contexto asiático, en contraste con América Latina y África, cuyos proyectos de industrialización y desarrollo fueron obturados en parte por los cambios en la fase del ciclo de acumulación que produjo la captura de sus economías por parte del capital financiero, y en parte por el accionar de las elites locales y los Estados-nación que no tuvieron capacidad de configurar una respuesta autónoma de base endógena a los embates de la economía mundo capitalista. Es por ello que, la creciente articulación al interior del SG y su progresivo dominio en el control y dinamismo del proceso acumulativo, presenta heterogeneidades internas que colocan al Este asiático en el centro del proceso de re-emergencia económica del Sur.

\section{Desafíos y posibilidades: resultados del boom demográfico del Sur Global. Mano de obra y demanda}

Este análisis del proceso acumulativo gana potencialidad al considerar la dimensión demográfica. Actualmente, el NG concentra menos del 15\% de la población total, y, como vemos en el Gráfico 20, para el año 2100 se estima que representará menos del 10\%. Es decir, que el espacio en el que se han constituido históricamente los centros de acumulación sistémicos verá acrecentar progresivamente su marginalidad en términos de representación demográfica. 
Gráfico 20. Evolución de la población mundial, Norte Global vs. Sur Global, proyecciones hasta 2100

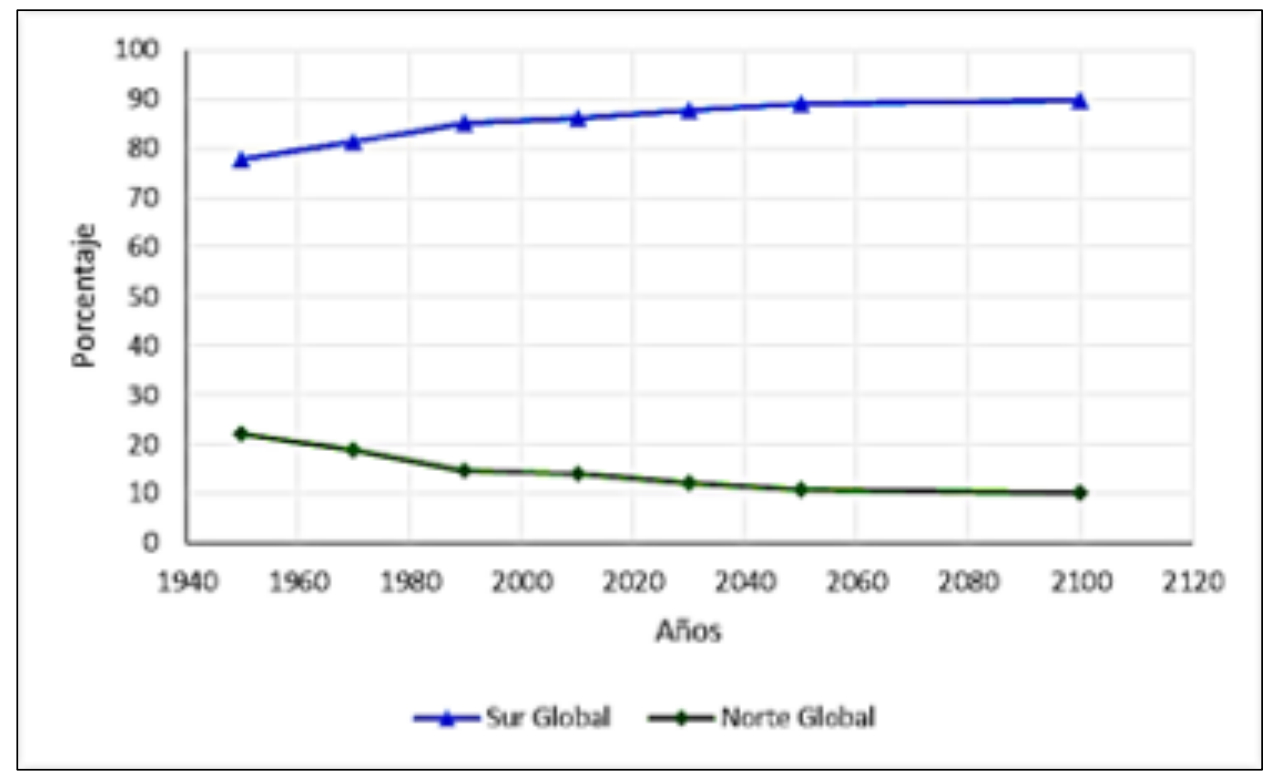

Fuente: Elaboración propia en base a datos de Naciones Unidas.

Cierto es que la población del SG nunca fue menor que las dos terceras partes del mundo (67\%), factor que, previo a la revolución industrial, le permitió disponer de un mayor producto global. A partir de 1950 esa brecha demográfica se amplió, producto de un mayor crecimiento relativo del SG que alcanzó a inicios del nuevo siglo el $80 \%$ del total mundial. Siguiendo las proyecciones demográficas para el año 2100 (Gráfico 21), el SG representará más del 90\% de la población mundial, siendo África el continente de mayor peso, seguido de cerca por Asia (United Nations, 2015).

El SG consolida su dominio demográfico a partir de la "bomba demográfica" que porta África, junto a uno de sus principales explosivos, la juventud comparada de su población. Allí, el $41 \%$ de la población son niños menores de 15 años, mientras que los jóvenes de 15 a 24 años constituyen el 19\%. América Latina y Asia tienen un porcentaje menor de niños (26\% y $24 \%$ respectivamente) y jóvenes $(17 \%$ y $16 \%$ respectivamente). En contrapartida, el NG lidera los 48 países que verán decrecer su población hasta en un 15\% para el 2050, contexto en el cual espacios como el europeo estarán por debajo de los niveles requeridos para el reemplazo de población.

Estas proyecciones plantean desafíos internos a cada una de las macro regiones del SG. La centralidad de África, proyectada a ser el continente más superpoblado, portadora asimismo de la estructura etaria más joven, impone el desafío de resolver cómo el creciente dinamismo acumulativo del SG se instala en la regiones más desfavorecidas, donde la rápida urbanización de la población toma lugar bajo una precaria desindustrialización (Resnick y Thurlow, 2015). Implica compatibilizar aumentos de productividad con generación de empleo (Banco Mundial, 2020), lo 
que, al mismo tiempo, demanda cambios cualitativos de envergadura en el posicionamiento en las cadenas globales que entrelazan sus países. Para ello, las articulaciones geopolíticas y geoeconómicas de base Sur-Sur, serán esenciales para la atracción condicionada de IED en áreas claves como infraestructura, y la retención de excedentes y capacidad tecnológica, pueden desencadenar procesos de desarrollo internos con creciente productividad y capacidad endógena de acumulación, mejorando las condiciones de salud y educación de generaciones futuras.

Gráfico 21. Proyección del crecimiento poblacional global por continentes (2020 a 2100)

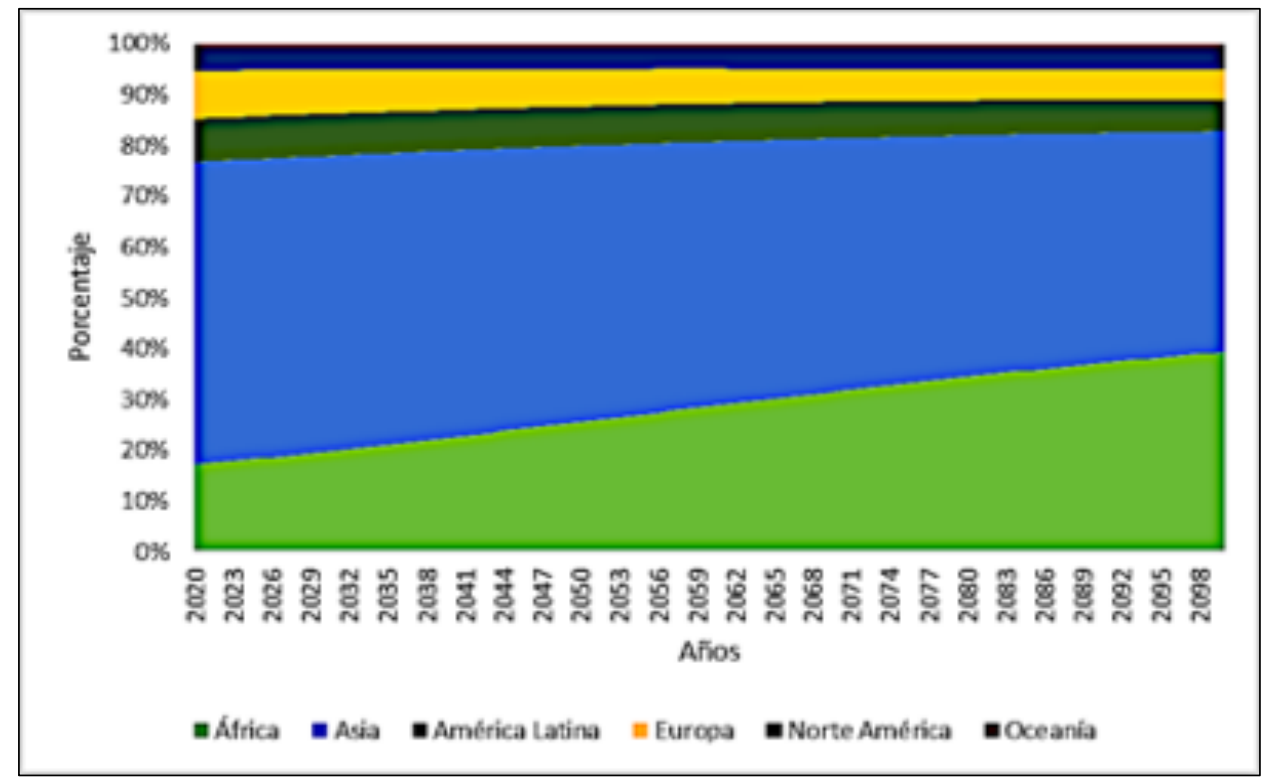

Fuente: Elaboración propia en base a datos de Naciones Unidas.

Ello, sin embargo, no estará exento de problemas en el campo socio-ambiental. El aumento de productividad y la introducción de tecnología en estos espacios, colisiona no sólo con los crecientes requerimientos de empleo y consumo, sino también con la sostenibilidad ambiental en un contexto de crisis climática, en espacios donde los recursos naturales son fuente planetaria para la continuidad del proceso acumulativo. Con otro alcance demográfico, pero potenciado por su estructural desigualdad, la proyección demográfica latinoamericana superando la población de América del Norte y Europa, en medio de una estructura de empleo informal cercana al $40 \%$ y un aferramiento a la explotación de sus recursos naturales, prescribe similares tensiones.

La tensión sobre la explotación de los recursos naturales se presenta como uno de los aspectos centrales en las relaciones al interior del SG. Estos insumos son centrales para Asia, particularmente para China - y progresivamente otros, como India-, que requieren de los mismos para profundizar sus procesos de acumulación. Frente a tal necesidad, Asia deberá mostrar capacidad de eludir las tensiones recolonizadoras y dar lugar a una transferencia de recursos y conocimiento capaz de potenciar los procesos de acumulación más diversificados, complejos y endóge- 
nos. Mientras ello demanda una lógica win-win largamente ausente en la dinámica del sistema mundo capitalista, queda aún abierto si ese proceso tomará lugar a medida que se profundice la presencia asiática dentro del SG y África en particular (Alves, 2013; Wang, 2014; Moyo, 2016; Jarso, 2018; Mohan, 2013).

La potenciación de esas tensiones entre macro regiones, como aquellas al interior de las mismas entre la complejidad tecnológica y la generación de empleo, constituye una plataforma problemática para pensar una progresiva redefinición en las formas acumulativas dominantes a partir del desarrollo de formas de producción, empleo y consumos alternativos. Mientras estos desafíos al interior del SG ganan fuerza, sus tensiones con el $\mathrm{NG}$, procurando preservar sus posiciones de dominio productivo y financiero, se acrecientan, al mismo tiempo que éste último enfrenta crecientes presiones migratorias del SG (Babaci-Wilhite, Geo-JaJa y Lou, 2013). Si bien esas presiones parcialmente entroncan con las demandas emergentes de un relevo demográfico insuficiente y un envejecimiento de su población - lo que explica el crecimiento migratorio hacia el norte-, chocan con las múltiples resistencias internas que procuran preservar intereses y carecen de predisposición a generar nuevos procesos redistributivos.

\section{Conclusiones}

El nuevo siglo es testigo de una "gran transformación” que desafía la configuración jerárquica interestatal y geográfica tradicional del SM vigente a finales del siglo $\mathrm{XX}$, producto de la emergencia del SG. Observamos ese ascenso como un gran movimiento de "placas tectónicas" al interior de la estructura del sistema mundo. Es decir, un fenómeno geo-económico y geopolítico con potencialidad de transformar los cimientos sobre los que se sostuvo la estructura y las jerarquías que dividen a las regiones y los países, con capacidad de redefinir la contradicción elemental y estructurante entre centro y periferia. Por primera vez en la historia del moderno sistema mundo el centro de acumulación material se encuentra fuera de occidente y su área de influencia. En otros términos, regresa hacia oriente, desplegando una interacción creciente entre las macro regiones que forman el SG. Ello tanto consolida una nueva unidad espacial donde se concentra el dinamismo del proceso de acumulación como conforma y expande en su interior heterogeneidades y divergencias de clara incidencia en la nueva geoeconomía y geopolítica global. Observamos este proceso a través de tres dimensiones: la dinámica económica, el dinamismo y el control estratégico en las cadenas de valor.

En relación a la dinámica, observamos que, luego de atravesar un siglo (18501950) de creciente periferialización, desindustrialización e incorporación subordinada a la división internacional del trabajo bajo el predominio del NG, el SG comenzó a recuperar sus posiciones económicas. Este proceso se remonta hasta la posguerra, y se da en el marco del despliegue de estrategias geopolíticas de contención del comunismo desplegadas por EE UU, observándose un quiebre a partir del comienzo del nuevo milenio, con el ingreso de China y su "carrera acelerada" hacia mejores posiciones económicas. En tanto que se ve con claridad en términos del PBI y del peso de las manufacturas en el SG, otros flujos comerciales y financieros complementan la comprensión del posicionamiento del SG y su crecimiento interno. Los datos dan cuenta del creciente peso mundial del comercio al interior del 
SG, el que ha sobrepasado los intercambios con el Norte y ha empatado el volumen comercial al interior del NG, en tan sólo veinte años. Asimismo, la IED ha jugado un papel importante en el ascenso del SG, primero en tanto receptor, pero también, y con un mayor peso, como exportador de IED hacia el mundo, en particular desde Asia hacia el resto del SG.

Bajo esta consolidación y creciente articulación interna del SG, que trasluce un progresivo proceso de reforzamiento auto-sustentado, se inserta la consideración de los aspectos asociados al dinamismo del proceso de acumulación. La creciente y combinada presencia de inversión en I+D y el aumento en la cantidad de patentamientos, dan cuenta de un proceso económico que tiende a controlar el componente tecnológico que dinamiza y sustenta su proceso de acumulación, lo que se traduce en un catch up, basado en la innovación productiva que posibilitó situar en el SG muchos eslabones claves dentro de las redes de producción global, a la vez que posibilitar la salida de la especialización subordinada a partir de un patrón de exportación más sofisticado. Bajo ese contexto, gana peso la tercera dimensión analítica, asociada al control sobre el proceso de acumulación. En tal sentido, junto a los aspectos antes señalados, se ha hecho visible el mayor peso que cobran las empresas trasnacionales del SG dentro del ranking 500 de Forbes, tomado como proxy de su performance económica.

Por lo tanto, las tres dimensiones consideradas (dinámica, dinamismo y control del proceso de acumulación) dan cuenta de un "movimiento de placas" con potencialidad para redefinir la configuración tradicional del moderno sistema mundo, a partir de un sostenido crecimiento y control intra-área de los flujos comerciales y de capitales. Esto fortalece su unidad, y le da sentido como área del mundo, a pesar de sus divergencias internas. La magnitud de los flujos ha superado aquella configuración tradicional NG-SG que dio ordenamiento a la jerarquía mundial. Tenemos, por lo tanto, una enorme trasformación geoeconómica, cuyo resultado es que, por primera vez en la historia del moderno sistema mundo, el epicentro del proceso acumulativo y las bases de la formación hegemónica se desplazan de Occidente y se localizan en el macro espacio donde reside la enorme mayoría de la población del mundo.

Ahora bien, aún cuando nuestro análisis empírico se concentró en ese "movimiento de placa ascendente", la evaluación de sus alcances demanda considerar un sinnúmero de tensiones y desafíos al interior del mismo y en sus relaciones con el NG. En relación a las primeras, señalamos cómo el proceso de explosión demográfica, y la fuerte dependencia en recursos naturales, impone múltiples desafíos asociados a la difícil compatibilización del requerido crecimiento de productividad y la introducción de la capacidad de aprendizaje tecnológico con la generación masiva de empleo y mejora en las condiciones de vida. Al mismo tiempo la expansión de la máquina acumulativa junto con la demográfica enfrenta la viabilidad de la preservación medioambiental. Estas tensiones en el campo ambiental y en las condiciones de vida coloca en agenda la necesidad de pensar formas materiales de reproducción alternativas.

El avance de esos desafíos tiene lugar bajo un emergente proceso geoeconómico y geopolítico resultante de las divergencias al interior del SG. Estas son el resultado del liderazgo y desigual comportamiento en la dinámica, dinamismo y control del proceso de acumulación por parte del Este asiático y su forma de vinculación con el resto del SG. Dicha divergencia, reabre los interrogantes sobre la reversión o 
recreación de relaciones asimétricas, expoliativas y creadoras de desigualdad que afectaron históricamente aquellos espacios más pobres como África, o desiguales, como América Latina.

La emergencia del SG se presenta como una oportunidad de desarrollo, así como también un desafío para poder reconfigurar su forma de integración al sistema mundo. Eso demandará que los nuevos actores globales, emplazados en el Sudeste asiático, estén dispuestos a facilitar articulaciones con "el resto" del SG, basadas en una complementariedad no jerarquizadora ni subordinante. También requerirá capacidad de ese "resto" de gestar procesos de acumulación e integración que rompan sus inercias primarizadoras y viabilicen redes económicas en las que el control de sus funciones claves recale dentro de sus fronteras, otorgándoles mayor grado de autonomía.

Finalmente, el SG $-\mathrm{y}$ el renovado liderazgo asiático al comando de Chinadeberá enfrentar desafíos y tensiones con el NG y su intento de preservar su campo hegemónico y espacios de relación con el SG. A esto se suma una condición también inédita en el moderno sistema mundo: la portación de una historia larga y una más reciente que contiene su revolución, que, en lo interno, marcaron límites al control del Estado por los actores capitalistas y, en lo externo, le permiten desarrollar una estrategia expansiva, sin "autorizaciones geopolíticas", apuntalada por una capacidad militar creciente.

La traducción de esa autonomía en nuevos meta-discursos, traducidos como "Consenso de Beijing" o la "Ruta de la Seda", donde domina un escenario win-win para el conjunto del SG (Jarso, 2018), tiene por delante el no predecible desafío de traducirse en procesos concretos. De ello y de la capacidad del SG no asiático de conjugar esa plétora de desafíos enunciados, dependerá que la transformación de gran escala que significa la irrupción del SG pueda dar vida a un nuevo y exitoso Bandung y una desmentida a aquellos que aún sostienen que el desarrollo de la periferia no logrará trascender el estatus de ilusión.

\section{Agradecimientos}

Quisiéramos agradecer en la Universidad Nacional del Litoral (UNL) y al Instituto de Humanidades y Ciencias Sociales (IHUCSO-CONICET-UNL), a Emilia Ormaechea y Joel Sidler, por su dedicada lectura y valiosos aportes, así como a los revisores por las observaciones que han ayudado a la mejora de este artículo.

\section{Referencias}

Alves, A. (2013). China's 'win-win' cooperation: Unpacking the impact of infrastructurefor-resources deals in Africa. South African Journal of International Affairs, 20(2), 207226. DOI: $10.1080 / 10220461.2013 .811337$

Amsden, A. (2003). Good Bye, Dependency Theory, Hello Dependency Theory. Studies in Comparative International Development, 38(1), 32-38. DOI: 10.1007/BF02686320 
Arrighi, G. (1990). The developmentalist illusion: a reconceptualization of the semiperiphery, in semiperipherial States in the world economy. En W. Martin (Ed.), Semiperipherial States in the world economy (pp. 11-42). London: Greenwood Press.

Arrighi, G. (1994). El largo siglo XX. Dinero y poder en los orígenes de nuestra época. Madrid: Ediciones Akal.

Arrighi, G. (1999). Globalization and Historical Macrosociology. En J. Abu-Lughod (Ed.), Sociology for the twenty first century (pp. 117-133). Chicago: University of Chicago Press.

Arrighi, G. (2003a). Spatial and Other "Fixes" of Historical Capitalism. Journal of WorldSystems Research, 10(2), 527-539.

Arrighi, G. (2003b). The rise of East Asia in regional and world historical perspective. En G. Arrighi, T. Hamashita y M. Selden (Eds.), The Resurgence of East Asia (pp. 1-16). Nueva York: Routledge.

Arrighi, G. (2007a). Adam Smith in Pekin. Madrid: Akal.

Arrighi, G. (2007b). La globalización, la soberanía estatal y la interminable acumulación del capital. En F. López Castellano (Coord.), Desarrollo: crónica de un desafio permanente (pp.183-216). Granada: Universidad de Granada.

Arrighi, G., y Drangel, J. (1986). La estratificación de la economía mundo: una exploración de la semiperiferia. Review (Fernand Braudel Center), X(1), 9-74.

Arrighi, G., Satoshi, I., y Irwan, A. (1993). The Rise of East Asia: One Miracle or Many? En R. A. Palat (Ed), Pacific Asia and the Future of the World Economy (pp.41-65). Westport: Greenwood Press.

Arrighi, G., Silver, B., y Brewer, B. (2003). Industrial Convergence, Globalization, and the Persistence of the North-South Divide. Studies in Comparative International Development, 38(1), 3-31.

Babaci-Wilhite, Z., Geo-JaJa, M., y Lou, S. (2013). China's aid to Africa: Competitor or alternative to the OECD aid architecture?. International Journal of Social Economics, 40(8), 729-743. DOI: 10.1108/IJSE-09-2012-0172

Babones, S. (2005). The Country-Level Income Structure of the World Economy. Journal of World-Systems Research, 11(1), 29-55. DOI: 10.5195/jwsr.2005.392

Bairoch, P. (1982). Economics and World History. Myths and Paradoxes. Chicago: University of Chicago Press.

Bairoch, P., y Wright, R. (1996). Globalization Myths. Reflection on Integration, Industrialization and Growth in the World Economy. Cambridge: UNCTAD.

Banco Mundial. (2020). Creating Jobs for Africa's Growing Population. New York: WEF.

Bernhardt, T. (2016). South-South trade and South-North trade:which contributes more to development in Asia and South America? Insights from estimating income elasticities of import demand. Cepal Review, (118), 97- 114. DOI: 10.18356/056e0f80-en

Broadberry, S., Fremdling, R., y Solar, P. (2014). Industry, 1700-1870. En S. Broadberry y K. H. O'Rourke (Eds.), Unifying the European Experience: An Economic History of Modern Europe, Volume 1: 1700-1870 (pp.164-186). Cambridge: Cambridge University Press.

Chang, H. J. (2002). Kicking Away the Ladder- Development Strategy in Historical Perspective. Cambridge: Anthem Press.

Dicken, P. (2011). Global Shift: Mapping the Changing Contours of the World Economy. Londres: Sage. 
Epstein, G. (2006). Financialization and the World Economy. Cheltenham: Edward Elgar Publishing.

Evans, P., Rueschemeyer, D., y Skocpol, T. (1985). Bringing the State Back In. Cambridge: Cambridge University Press.

Fernández, V. R. (2015). Global Value Chains in Global Political Networks: Tool for development or neoliberal device? Review of Radical Political Economy, 47(2), 209230. DOI: $10.1177 / 0486613414532769$

Fenández, V. R. (2017). La trilogía del erizo zorro. Santa Fe: Anthropos.

Friedman, T. (2005). La tierra es plana. Nueva York: Farrar, Straus and Giroux.

Frobel, F., Heinrichs, O., y Kreye, J. (1980). The New International Division of Labor. Cambridge: Cambridge University Press.

Fukuyama, F. (1988). El fin de la historia (The national interest). Recuperado de https://www.alianzaeditorial.es/minisites/manual_web/3491295/CAP8/1_FindelaHistori a.pdf

Gellert, P. (2010). Extractive Regimes: Toward a Better Understanding of Indonesian Development. Rural Sociology, 75(1), 28-57. DOI: 10.1111/j.1549-0831.2009.00001.x

Gereffi, G. (2001). Las cadenas productivas como marco analítico para la globalización. Problemas del Desarrollo, 32(125), 9-37. DOI: 10.22201/iiec.20078951e.2001.125.7389

Gereffi, G., Humphrey, J., Sturgeon, T., Kaplinsky, y Raphael. (2001). Introduction: Globalisation, Value Chains and Development. IDS Bulletin, 32(3), 1-8. Recuperado de https://www.ids.ac.uk/download.php?file=files/dmfile/gereffietal323.pdf

Glassman, J. (2018). Drums of wars, Drums of development: The Formation of a Pacific Ruling Class and Industrial Transformation in East and Southeast Asia, 1945-1980. Boston: Brill.

Gunder Frank, A. (1998). ReOriente. Economía Global en la era asiática. Berkley: University of California Press.

Hall, T. (1996). World System and Evolution: An Appraisal. Journal of World-Systems Research, 2(1), 201-238. DOI: 10.5195/jwsr.1996.86

Hamashita, T. (1994). The Tribute System and Modern Asia. En A. J. Latham y H. Kawakatsu (Eds.), Japanese Industrialization and the Asian Economy (pp. 91-107 ). Londres y Nueva York: Routledge.

Hopkins, T., \& Wallerstein, I. (1977). Patterns of development of the modern worldsystem. Review (Fernand Braudel Center), I(2), 111-145.

Hopkins, T., \& Wallerstein, I. (1986). Commodity Chains in the world-economy prior to 1800. Review (Fernand Braudel Center), X(1), 157-170.

Hudson, R. (2016). Rising powers and the drivers of uneven global development. Area development and policy, 1(3), 279-294. DOI: 10.1080/23792949.2016.1227271

Ikeda, S. (1996). The History of the Capitalist World-System vs. the History of EastSoutheast Asia. Review (Fernand Braudel Center), XIX(1), 44-77.

Jarso, G. (2018). The Beijing consensus versus the Washington consensus: The dilemma of Chinese engagement in Africa. African Journal of Political Science and International Relations, 12(1), 1-9. DOI: 10.5897/AJPSIR2016.0920

Kaplinsky, R. (2016). Global value chains: where they came from, where they are going and why this is important. En J. Weiss y M. Tribe (Eds.), Routledge Handbook of industry and development (pp184-203.). Londres y Nueva York: Routledge. 
Karatasli, S. S. (2016). The Capitalist World-economy in the Longue Durée: Changing Modes of the Global Distribution of Wealth, 1500-2008. Sociology of Development, 3(2), 163-196.

Karatasli, S. S. (2018). Great Convergence or the Third Great Divergence: Changes in Global Distribution of Wealth, 1500-2008. En P. Korzeniewicz.(Ed.), The World System as a Unit of Analysis: Past Contributions and Future Advances (pp.36-49). Nueva York: Routledge,

Korzeniewicz, R. P., y Moran, T. (1997). World-economic Trends in the Distribution of Income, 1965-1992. American Journal of Sociology, 102(4), 1000-1039.

Lourenço, A. L. (2005). Semiperiferia: uma hipótese em discussão. Economia e Sociedade, 14(1), 177-186. Recuperado de http://www.eco.unicamp.br/images/arquivos/artigos/589/08-Nota1.pdf

Mahutga, M., y Smith, D. (2011). Globalization, the structure of the World Economy and Economic Development. Social Science Research, (40), 257-272.

Milberg, W., y Winkler, D. (2009). Globalization, Offshoring and Economic Insecurity in Industrialized Countries. Nueva York: United Nations.

Mohan, G. (2013). Beyond the Enclave: Towards a Critical Political Economy of China in Africa. Development and Change, 44(6), 1255-1272. DOI: 10.1111/dech.12061

Moyo, S. (2016). Perspectives on South-South relations: China's presence in Africa. InterAsia Cultural Studies, 17(1), 58-67. DOI: 10.1080/14649373.2016.1138615

Nayyar, D. (2013). Catching Up. Developing Countries in the World Economy. Oxford: Oxford University Press.

Ohmae, K. (1985). Triad power. The coming shape of global competition. Nueva York: Free Press.

Pasciuti, D., y Payne, C. (2017). Illusion in crisis? World-economic and zonal volatility 1975-2013. En P. Korzeniewicz (Ed.), The World-System As Unit of Analysis: Past Contributions and Future Advances (pp.50-133). Nueva York: Routledge. DOI: 10.4324/9781315101422-6

Pietrobelli, C., y Rabellotti, R. (2011). Global value chains meet innovation systems: are there learning opportunities for developing conuntries? World Development, 39(7), 1261-1269. DOI: 10.1016/j.worlddev.2010.05.013

Prebisch, R. (1986). El desarrollo económico de la América Latina y algunos de sus principales problemas. Desarrollo Económico, 26(103), 479-502.

Reifer, E. (2011). Global Inequalities, Alternative Regionalisms and the Future of Socialism. Journal für Entwicklungspolitik, XXVII(1), 72-94.

Resnick, D., y Thurlow, J. (2015). African Youth and the Persistence of Marginalization: Employment, politics, and prospects for change. Nueva York: Routledge.

Sala-i-Martin, X. (2006). World Distribution of Income: Falling Poverty and ... Convergence, Period. Quarterly Journal of Economics, 121(2), 351-397. DOI: 10.1162/qjec.2006.121.2.351

Sanderson, S. (2005). The World System Analysis after thirty years: should it rest in peace? International Journal of Comparative Sociology, 46(3), 186-197. DOI: $10.1177 / 0020715205058606$

Santarcángelo, J., Schteingart, D., y Porta, F. (2017). Cadenas Globales de Valor: una mirada crítica a una nueva forma de pensar el desarrollo. Cuadernos de Economía Crítica, , 4(7), 99-129. 
Stubb, R. (1999). War and Economic Development: Export-Oriented Industrialization en East and Southeast Asia. Compartive Politics, 31(3), 337-355.

Sugihara, K. (2003). The East Asian Path of Economic Development: A Long-term Perspective. En G. Arrighi, T. Hamashita y M. Selden (Eds.), The Resurgence of East Asia. 500, 150 and 50 years perspective (pp.78-123). Londres: Routledge.

Suwandi, I., Jonna, R., y Foster, J. (2019). Global Commodity Chains and the New Imperialism. Monthly Review, 70(10), 1-24. Recuperado de https://monthlyreview.org/2019/03/01/global-commodity-chains-and-the-newimperialism/

UNCTAD. (1999). World Investment Report 1999: Foreign Investment and the challenge of development. Nueva York: United Nations. Recuperado de https://unctad.org/en/Docs/wir1999_en.pdf

UNCTAD. (2015a). Global Value Chains and South South trade. Geneva: UNCTAD. Recuperado de https://unctad.org/en/PublicationsLibrary/gdsecidc2015d1_en.pdf

UNCTAD. (2015b). Informe sobre las inversiones en el mundo: reforma de la gobernanaza internacional en materia de inversiones. New York: United Nations. Recuperado de https://unctad.org/es/PublicationsLibrary/wir2015overview_es.pdf

UNESCO. (2017). UIS Fact Sheet No. 42. Global Investment in RyD. UNESCO. Recuperado de https://unesdoc.unesco.org/ark:/48223/pf0000247772

United Nations. (2015). World Population Prospects. Nueva York: United Nations. Recuperado de https:/www.un.org/en/development/desa/publications/world-populationprospects-2015-revision.html

Wade, R. (1990). Industrial Policy in East Asia: Does It Lead or Follow the Market? . En G. Gereffi y D. Wyman (Eds.), Manufacturing Miracles: Paths of Industrialization in Latin America and Latin America (pp.32-51). Princeton: Princeton University Press.

Wallerstein, I. (1975). Class Formation in the Capitalist World-Economy. Politics and Society, 5(3), 367-375. DOI: 10.1177/003232927500500304

Wallerstein, I. (1976). The Modern World-System: Capitalist Agriculture and the Origins of the European World-Economy in the Sixteenth Century (pp.229-233) Nueva York: Academic Press.

Wallerstein, I. (2004). World System Analysis: an introduction. Durham, NC: Duke University Press.

Wallerstein, I. (2011). Structural Crisis in the World-System: Where Do We Go from Here? Monthly Review, 62(10). DOI: 10.14452/MR-062-10-2011-03_2

Wang, E. (2014). China in Africa: presence, perceptions and prospects. Journal of Contemporary China, 23(90), 1012-1032. DOI: 10.1080/10670564.2014.898888

Wolf, M. (2011). Financial Times, 4 de enero. Recuperado de https://www.ft.com/content/072c87e6-1841-11e0-88c9-00144feab49a 